\title{
Cambios en el paisaje hidroagrario. ¿La Revolución un detonante?: el caso de San Luis Potosí (1910-1940)
}

\author{
Antonio Escobar Ohmstede* \\ CIESAS, D.F.
}

El presente artículo analiza los factores que llevaron a la reestructuración del paisaje agrario e hídrico en los valles rioverdenses en el estado de San Luis Potosí, en la transición del siglo XIX al siglo xx. Busca observar cómo ciertos factores externos trastocaron los sistemas de riego construidos por las propiedades privadas desde el periodo colonial, cuando las tierras y las aguas pasaron a formar parte de los ejidos constituidos a partir de la Reforma Agraria en el siglo xx.

(Sistemas de riego, pueblos, haciendas, legislación, juntas de agua)

\section{INTRODUCCIÓN}

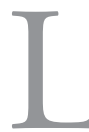

a historiografía se ha preocupado de manera constante de los diversos efectos que tuvo la suma de las variadas manifestaciones violentas o pacíficas en contra del largo mandato presidencial de Porfirio Díaz, algunas de ellas son las formas en que las modificaciones agrarias fueron vividas, sentidas e imaginadas por los diversos actores sociales; sin embargo, los impactos que éstas tuvieron en torno al acceso y distribución del recurso hídrico han sido tratados de manera insuficiente; por lo que este artículo busca analizar, en un espacio social ubicado al sureste del actual estado de San Luis Potosí, ${ }^{1}$

*ohmstede@ciesas.edu.mx Agradezco los comentarios de los dictaminadores anónimos que me permitieron puntualizar varios aspectos de este estudio; sin embargo, la responsabilidad de lo que aquí se presenta recae en el autor.

${ }^{1}$ En un trabajo que se encuentra en prensa, titulado: "Un espacio agrícola, hídrico y poblacional: los valles rioverdenses de San Luis Potosí en la primera mitad del siglo xx", analizo el incremento de la producción de maíz, frijol, caña de azúcar, así como la citrícola, esta última se dirigía en $70 \%$ a Guadalajara y el resto a las ciudades de México, Tampico, Monterrey e Irapuato. Mostrando la manera en que los valles se encontraban 
cómo podemos percibir a través de las dotaciones agrarias, las divisiones de las haciendas y el acceso a los recursos naturales por parte de los ejidos, la manera en que se ve afectado el abasto de agua de riego, no como un elemento de justicia social, sino quizá, como parte del poco conocimiento de aquellos que encabezaron el reparto, los ingenieros, que poco conocían la utilización de los nichos ecológicos e intereses productivos, sociales e incluso culturales de los diversos actores sociales (Ervin 2007, 537-570; Palacios 2000, 431-476; Boyer 2007, 91-138), que en algunos casos fueron utilizados como parte del poder político de la entidad para definir las dotaciones agrarias e hídricas en contra de algún opositor político o social. ${ }^{2}$

Después de las luchas armadas en diversas partes de México, comenzaron a desarrollarse cambios en la tenencia y, por lo tanto, en la estructura de la tierra que condujeron a transformaciones en los derechos y las formas de gestión del agua en muchos de los sistemas de riego existentes, procesos que requieren ser estudiados y analizados en su debido contexto. Existían, desde el periodo colonial, sistemas de riego en los que predominaban las pequeñas propiedades; los que convivían con pequeñas y grandes propiedades; y los que eran parte de una sola propiedad, los cuales al sobrevenir la reforma agraria se desagregaron entre ejidos, múltiples pequeñas propiedades o distritos de riego (Sandré y Sánchez 2011, 11-81). Hasta el momento se han realizado estudios historiográficos para los casos del Estado de México, Chihuahua, San Luis Potosí, Puebla, La Laguna, Michoacán y Morelos (Valladares 2003; Tortolero 2008; Picard-Ami 1980; Sánchez 2005 y 2008, I, 375-400; Mendoza 2005, 221-236; Palerm 2005, 263-288; Fitting 2007, 37-70; Cas-

integrados en un mercado local, regional y nacional, y analizando como muchos de los cambios se debieron a los cambios en la tenencia de la tierra y a las dotaciones de agua que se definieron ya entrados los años treinta del siglo XIx. Por lo que no es un objetivo de este artículo realizar el papel de la "región" en un mercado nacional. Para ver la dimensión económica de la revolución sugiero que se vea a Knight 2010, 473-502.

${ }^{2}$ No es el objetivo del artículo abundar en el papel de los ingenieros posrevolucionarios, sino solamente acotar que funcionaron como intermediarios y muchos de sus informes sirvieron o no, para tomar decisiones políticas. Sin duda, aun falta mucho para saber del papel real a favor o en contra de los pueblos y propietarios privados, aun cuando haya indicios para algunas regiones del país. 
tañeda 2005, 237-262 y 2008, II, 423-440; Gómez 2003 y 2007 , 133-165; Camacho 2008, i, 287-31 1; Escobar Ohmstede 2011, 263311; Romero 2003, 21-26 y 2007, 117-142); sin embargo, aun falta dilucidar los efectos en otras partes de México (Oaxaca, Sonora, Tamaulipas, Veracruz y Guerrero, por mencionar algunos) con el fin de tener una visión adecuada, que nos permita observar y quizá aseverar de manera más adecuada que no existió una reforma agraria sino varias y con características diversas, así como la manera en que éstas impactaron en los recursos hídricos y boscosos, así como en los comportamientos sociales y culturales de los actores. Esta última reflexión no parte de una perspectiva muy novedosa, sino que sólo deseo puntualizar el dejar de lado, más no desechar, los marcos generales que oscurecen las visiones sobre diversos espacios sociales y paisajes que son complejos y cambiantes.

Sin pretender hacer un análisis desde la perspectiva de la denominada historia ambiental, tendremos en cuenta los cambios en el paisaje, vistos como procesos históricos que se desenvuelven en espacios culturales creados y observados por el hombre, es decir, como los aspectos de un terreno dado en un territorio que rodea un lugar determinado y las connotaciones del ambiente espacial que caracterizan a una localidad. Sin duda, los paisajes, a través de los cuales percibimos la naturaleza, son en sí hechura humana. Con una perspectiva del cambio del paisaje, podemos observar los espacios como recursos materiales definidos, los cuales se crean y recrean a partir de las diversas actividades que los actores sociales llevan a cabo en momentos particulares, por lo que sus posibles límites en sí son variables. Por lo que también una pregunta, que cruza el presente artículo, es si el proceso de otorgamiento de tierras y aguas ejidales elaborado a partir de la intervención estatal puede llevarnos a considerar que este proceso provocó una especie de "tragedia" o Némesis (pensado éste como un evento desafortunado al cual seguirán sucesos que compensarán las pérdidas del primero) en las áreas rurales, al irse fraccionando los sistemas de riego que habían construido las diversas unidades productivas agrarias durante el paso de los siglos, los cuales fueron dejados o fracturados por los "nuevos" propietarios de la tierra y el agua, esto es, los ejidos posrevolucionarios. 
Observaremos los procesos que enfrentaron las propiedades privadas posteriores a la reforma agraria en un espacio que puede compararse al entorno morelense y al poblano, en términos de estructuras agrarias, manejo del agua y el papel de los diversos grupos de poder regional, como el de Rioverde, San Luis Potosí. Para poder analizar de una manera adecuada los procesos debemos comprender el desarrollo posrevolucionario en Rioverde: la legislación agraria e hídrica que se desarrolló a partir de 1910 en México; el entorno geográfico; el tipo de unidades productivas que existían; los grupos de poder y el surgimiento de los ejidos; y cómo éstos, a partir de las dotaciones comenzaron a fracturar los sistemas de riego que los propietarios habían elaborado durante varias décadas.

\section{UN ACERCAMIENTO A LOS ESTUDIOS DEL TEMA}

Debo de aclarar que dentro de la legislación posrevolucionaria, un factor importante fue la formación de Juntas de Aguas y de Asociaciones de Usuarios, lo que parecía establecer una centralización de la gestión del agua en todos los sistemas de riego existentes; sin embargo, no sólo fue una especie de monopolio en manos de las juntas de aguas o de las directivas de las asociaciones de usuarios, esto también se pretendía desde la Secretaría de Agricultura y Fomento (SAyF). La respuesta de los diversos usuarios dependió, en gran medida, de la existencia de una tradición en la gestión del agua, pero también de la estructura agraria previa y de su reacomodo como consecuencia de la reforma agraria (Palacios 2009, 217-225; Gómez 2007, 133-165), lo que generó importantes decisiones por parte de los variados actores sociales, este escenario se desarrolló en el valle rioverdense.

Sin embargo, para el caso de Morelos, la creación de Juntas de Aguas -instituciones centralizadas de gestión del agua- no funcionó como una alternativa viable en la resolución de los conflictos entre los usuarios en virtud de su falta de experiencia en la organización autónoma con respecto al aprovechamiento de los recursos hidráulicos (Valladares 2003). De esta forma, los integrantes de las juntas simplemente no emprendían acciones con la finalidad de solucionar 
los conflictos o bien se inclinaban hacia ciertos intereses económicos y políticos, provocando la negativa de los usuarios a acatar sus disposiciones. En otras palabras, las actuaciones de los representantes de las juntas carecían de legitimidad frente a la mayoría de los consumidores.

Lo que se observa para el caso de Morelos, los valles rioverdenses potosinos, el Valle de Chalco (Tortolero 2008), Nexapa, Puebla (Gómez 2007, 133-165) y La Laguna (Romero 2007, 135-141) es muy parecido a lo analizado por Rocío Castańeda (2005a) para el sistema de riego del río Cantarranas, en Atlixco, Puebla. El escenario agrario de Atlixco se caracterizaba por el predominio de haciendas con derechos de agua y una infraestructura hidráulica que se remontaba a finales del siglo Xvi (Camacho 2007, 5-22). En la década de 1920 se presentaron las primeras dotaciones de ejidos y con ello se dividieron las asignaciones de agua que habían disfrutado previamente las propiedades privadas. La modificación de los derechos hídricos impuso la necesidad de elaborar un reglamento que reordenara completamente la distribución del líquido de acuerdo con las nuevas circunstancias, asunto que se llevó a cabo en 1929, en cumplimiento de la ley de aguas que se había emitido en ese mismo año.

El principal problema que tuvo que enfrentar la SAyF fue que todos los usuarios creían merecer volúmenes mayores a los que se les habían asignado en el reglamento. De hecho, todos robaban el agua y se obstaculizaban unos a otros en sus aprovechamientos. Tomaban de más cuando podían, aunque no contaban con plena seguridad sobre el momento en que recibirían más o menos agua, esta situación provocaba la ausencia de parámetros para decidir qué superficies de riego sembrar y el riesgo latente de perder las cosechas si no lograban obtener el agua necesaria para sus sembradíos. La inseguridad permanente tenía como resultado el incremento de la conflictividad. Por otra parte, los usuarios se rehusaban a participar en la construcción de una infraestructura adecuada a las nuevas asignaciones consideradas en el reglamento, pues ello implicaba dar su consentimiento a las cantidades que los ingenieros de la SAyF les habían destinado. 
La creación de una Junta de Aguas que debía asumir la resolución de los problemas tampoco aportó buenos resultados en los primeros ańos por causas similares a las de Morelos, esto es, la falta de experiencia con respecto a un manejo centralizado del agua. A lo anterior, habría que agregar que los miembros de la Junta eran propietarios de las antiguas haciendas o representantes de las fábricas textiles establecidas en las riberas del río Cantarranas, las cuales utilizaban agua para producir fuerza motriz. Esta situación se caracterizó por una intensa pugna por la tierra y por el agua que hizo sospechar a los ejidatarios que los integrantes de la junta se inclinaban por los intereses de las haciendas y de las fábricas, lo que derivaba en la indiferencia o rebeldía declarada contra cualquier disposición emanada de la Junta. Sandré (2005, 289-322) en su trabajo sobre las Juntas de Aguas en el Estado de México, en los años que van de 1920 a 1950, llega a conclusiones similares.

Aun no se han realizado muchos estudios pormenorizados sobre el funcionamiento de las Juntas de Aguas en Morelos y Atlixco después de 1940, lo que podría arrojar luz acerca de si los regantes lograron crear o restablecer posibilidades de un acuerdo, o si se consolidó y aceptó la gestión centralizada de esos sistemas de riego. ${ }^{3}$ Sin embargo, en ese aspecto el trabajo de González Huerta (2000, II, 133-210) es ilustrativo sobre la forma en que los nuevos usuarios encontraron, con el paso de los años, los mecanismos para lograr el funcionamiento del sistema de riego sin intervención de las instancias del gobierno federal. Su conclusión es que si bien este sistema se vio afectado por los mismos problemas observados en Morelos y en Atlixco, e inicialmente la Junta de Aguas surgió como una organización subordinada a las órdenes de la Secretaría de Agricultura y Fomento, paulatinamente la necesidad de asegurar el suministro del líquido precisó que la organización de regantes tomara decisiones por su cuenta y esta-

${ }^{3}$ En el caso de Morelos un estudio sobre el funcionamiento reciente de las organizaciones de riego en el río Cuautla, en las que se encuentran presentes ejidos, ha demostrado que frente a la poca disponibilidad de agua los ejidos han sido capaces de organizarse y de alcanzar acuerdos informales y flexibles (Palerm, Pimentel y Salcedo 2000, II, 7396). Respecto a Atlixco, Ocampo (1997, I, 367-398) y para el del valle de Tehuacán, Fitting (2007, 37-70); para el de Izúcar, Puebla, Gómez (2003, 359-386). 
bleciera una distribución con base en criterios locales, dejando al margen las mediciones realizadas por la misma Secretaría, en un primer momento, y por la Secretaría de Recursos Hidráulicos (SRH), posteriormente. De esta forma, la Junta de Aguas en realidad funcionó de manera autónoma, aplicando sus propios criterios para regular las relaciones entre los usuarios y dar solución a los problemas que surgieron entre ellos, reelaborando en la práctica buena parte de las disposiciones de los reglamentos formulados en distintos momentos por las dos secretarías (Sandré y Sánchez 2011).

Como se puede apreciar, un aspecto que debe profundizarse tiene que ver con la forma en que los participantes de los sistemas de riego se adaptaron o lograron encontrar vías de acuerdo cuando carecían de experiencia organizativa y de manejo de gestión centralizada en los ańos posteriores a las décadas de 1920-1940, lo cual también implicó cambios en las estructuras sociales y de intercambio entre las mismas localidades. ${ }^{4}$ En otras palabras, no se trata sólo de demostrar la destrucción de las obras hidráulicas y mostrar el fracaso de los nuevos grupos de regantes en la gestión del agua, sino de buscar sus experiencias en la creación de acuerdos y de construcción de nuevas obras y, sobre todo, de la manera en que lograron la administración del agua con o sin la ingerencia del Estado, fuera a través de retomar viejos reglamentos, adecuarlos o sencillamente... mantener formas de negociación y acuerdos utilizados durante los diversos momentos históricos.

¿Pero, qué ocurrió con aquellos sistemas en los que sí había el precedente de una gestión centralizada previa? Ésta podía haber estado encabezada por comisiones dependientes de ayuntamientos, como sucedió en Oaxaca, San Luis Potosí, Puebla, el Estado de México y Michoacán o por comisiones elegidas en asambleas de regantes. Desconozco si hay en la actualidad algún trabajo que aborde un sistema de riego correspondiente a la modalidad del ayuntamiento como director de la gestión del agua. Con respecto a la se-

${ }^{4}$ Rodríguez Meza (2000, II, 345-406) ha abordado el caso del Comité de Vigilancia de los Ríos Atoyac y Nexapa, organización que ha funcionado al margen del reconocimiento de la Secretaría de Recursos Hidráulicos y sus sucesoras la Secretaría de Agricultura y Recursos Hidráulicos y la Comisión Nacional del Agua. 
gunda idea, existe un trabajo sobre las comunidades de riego de los municipios de Ciudad Camargo y La Cruz, Chihuahua, las cuales derivaban agua del río Conchos (Castañeda 1995). Estas comunidades funcionaban desde el siglo XIX a través de comisiones que asumían las tareas de la gestión del agua, es decir, la distribución del agua, el mantenimiento y la construcción de nuevas obras, el manejo de conflictos y la administración de los recursos económicos de las comunidades. Los ayuntamientos habían desempeñado un papel importante como respaldo de las decisiones adoptadas por las asambleas y como medios de coerción hacia aquellos que no cumplieran con sus obligaciones hacia las comunidades. Sin embargo, la estructura agraria en las distintas comunidades difería. En la de San Rafael, ubicada en el municipio de La Cruz, un hacendado y otros grandes propietarios habían ocupado la mayor parte de la tierra de riego de la comunidad en contraposición a un grupo de pequeños propietarios. Por el contrario, en las comunidades del municipio de Ciudad Camargo prevalecían las pequeńas propiedades.

Las consecuencias de la reforma agraria y de las disposiciones centralizadoras de la gestión del agua fueron distintas para los dos casos. En la comunidad de San Rafael, las decisiones habían sido una prerrogativa de los grandes propietarios hasta principios de la década de 1920, situación que explica porque en un reglamento, formulado por el mayor propietario de la comunidad y aprobado por el gobierno del estado en 1908, se estipulaba que los votos para aprobar las decisiones debían computarse a razón de un voto por suerte de tierra. ${ }^{5}$ Cuando se llevaron a cabo las primeras dotaciones de ejidos se impuso la necesidad de modificar las asignaciones de agua de los grandes propietarios y, por lo mismo, de reglamentar nuevamente la acequia de la comunidad. La intervención de la SAyF favoreció el surgimiento de iniciativas de los pequeños propietarios de participar de manera más activa en la toma de decisiones, luchando porque los votos se contaran a razón de uno por propietario. La práctica de esta forma de computar, a partir de 1931, dio lugar a que los pequeńos propietarios, siendo más numerosos, asumieran el control de la ges-

\footnotetext{
${ }^{5}$ Una suerte equivalía a 5.6 hectáreas (Castañeda 1995, 109).
} 
tión. ${ }^{6}$ Con todo, comenzaron a enfrentar tropiezos como consecuencia de su inexperiencia en el manejo de los asuntos de la comunidad. Como podemos ver, la experiencia previa de gestión centralizada no fue una garantía de que las disposiciones de la SAyF relativas a la reglamentación y a la centralización de la gestión del agua no afectaran los sistemas de riego, en virtud de que el reparto de tierras y aguas podía alterar los antiguos arreglos para ejercer la representatividad de las organizaciones. En casos como éste, también cabe llamar la atención sobre el hecho de que es preciso rescatar a través de la práctica de estos grupos la reanudación de los arreglos y acuerdos, y la reconstrucción de las antiguas obras o la construcción de nueva infraestructura.

Por otro lado, al emitirse las leyes de 1929 y 1934, que imponían la intervención de la SAyF en la organización de los usuarios, las comunidades no manifestaron rechazo, posiblemente porque esas disposiciones no alteraban su funcionamiento previo. Así, aceptaron la etiqueta de "sociedades de usuarios" y presentaron sus antiguos reglamentos para la aprobación de la SAyF. Con todo, no abandonaron su antigua denominación de comunidades, sino que a ésta agregaron su nueva etiqueta, por ejemplo la de San Francisco de Paula se nombró "Sociedad de Usuarios de la Comunidad San Francisco de Paula". En el caso de las comunidades de riego de Ciudad Camargo, no rechazaron las disposiciones gubernamentales en la medida en que no significaron cambios importantes en su funcionamiento interno. Tampoco demandaron la intervención de la SAyF para resolver los conflictos cotidianos comunales. Así, continuaron marchando como lo habían hecho hasta entonces, bajo una forma centralizada que no requería de la intervención gubernamental para manejarse de manera eficaz. En cambio, cuando su autonomía se vio amenazada, sí manifestaron oposición hacia la intervención del gobierno federal. Es decir, las medidas de la federación fueron aceptadas mientras no intervinieran en sus asuntos internos y sus decisiones básicas. En cambio, cuando las premisas de su autonomía organizativa podían verse afectadas entonces sí mostraron resistencia.

${ }^{6}$ Véase también el caso de valle de Allende, Chihuahua (Castañeda 2003, 18-27). 


\section{RECORRIDO POR LA LEGISLACIÓN}

El artículo 27 de la Constitución de 1917 incidió directamente en torno a como se podría reglamentar de manera posterior el tema hídrico, el cual estableció que la nación era la propietaria originaria de las tierras, las aguas y el subsuelo comprendidos dentro de su territorio (Núñez 2009, 127-228). Se ratificaba el contenido de la ley de diciembre de 1910 que definía qué corrientes podían ser consideradas de propiedad federal haciendo a un lado los criterios de navegabilidad y flotabilidad que habían sido esenciales en la legislación de 1888 y que tanta controversia habían causado. Se adoptaron de manera definitiva los conceptos de dominio público y de propiedad inalienable e imprescriptible de la nación sobre los tipos de corrientes (Núñez 2009, 141, 163-169), propiedad que sería ejercida por el gobierno federal como representante de la nación (Aboites 1988, 88).

En la década de 1920 se comenzó a generar un proceso de transferencia de derechos de agua a los ejidos, pero en las leyes y decretos que inicialmente normaron las restituciones y dotaciones de tierras nada se dijo acerca del elemento hídrico (Escobar Ohmstede y Sandré 2007, 70-87; Aboites 2008, I, 85-102). Fue hasta el 30 de abril de 1926 que se emitió una reglamentación más precisa en relación con las restituciones y dotaciones de aguas, en la cual casi se daba a entender que se les había "olvidado" el agua en las disposiciones relativas a la tierra emitidas después del artículo 27, estableciéndose que cuando hubiera varias solicitudes sobre una misma corriente, ninguna de ellas se debía resolver de manera aislada, sino que se debía realizar un plan general de distribución.

También se consideró que los ejidos podían obtener tierras de riego por restitución o por dotación, en cuyo caso se les asignaría un volumen que se fijaría en relación con el total de líquido de que disponían las fincas afectadas y la superficie total que regaban. Esta accesión podría ser obtenida de manera separada cuando por cualquier razón no se entregara de manera inmediata el volumen de agua correspondiente a las tierras consideradas de riego dentro de la restitución o la dotación. Un año después, se expidió la ley de dotaciones y restituciones de tierras y aguas, la cual era reglamentaria del 
artículo 27 de la Constitución. Una disposición era en torno a las obras hidráulicas: establecía que dentro de las dotaciones de aguas quedaban excluidas las construcciones permanentes de captación, derivación y conducción destinadas a irrigar terrenos que no formaran parte del ejido; también se excluían aquellas cuya finalidad fuera regar tanto tierras ejidales, como aquellas que hubieran quedado en manos de los propietarios afectados (Fabila 1981, 405-426 y 429-455). Este hecho traería connotaciones sociales importantes, puesto que la continuidad del dominio sobre la infraestructura hidráulica por parte de los afectados permitiría seguir ejerciendo el control y manejo sobre la distribución del agua en detrimento de los ejidatarios y otro tipo de usuarios, como podrían ser las Juntas de Agua. Entre 1926 y 1929 se cubrió el vacío con respecto al tema tierra, pero la propia ley de aguas se había quedado atrasada, y fue sólo hasta 1929 que se modificó con la finalidad de incorporar en ella las medidas que concernían al reparto de tierras y aguas. De esta manera, la ley de aguas de agosto de 1929 estableció nuevas reglas con respecto al uso del agua, derogó la de 1910 (Lanz 1982, II, 113-132), y puso de manifiesto la posibilidad de modificar los derechos de los antiguos concesionarios cuando así lo exigiera el cumplimiento de las leyes agrarias.

La ley de 1929 instituyó la formación de organizaciones denominadas "Asociaciones de Usuarios", las cuales serían obligatorias cuando se tratara de aprovechamientos colectivos realizados a partir de una sola toma, ${ }^{7}$ y serían regidas por juntas directivas, cuyas funciones consistían en dirigir la gestión del líquido en sus respectivas agrupaciones a la vez que actuarían como agentes del ejecutivo dentro de ellas y sus resoluciones serían avaladas por la SAyF. Pero tenían la obligación de rendir informes sobre la resolución de conflictos y la administración de los sistemas de riego a la Secretaría, como pudimos ver brevemente en el apartado anterior.

Las transformaciones fueron en dos sentidos: por una parte, el ingreso de los ejidos en el escenario agrario (compitiendo con los ayuntamientos y propietarios privados, así como con pueblos) y la redistribución del agua que implicó la desaparición de arreglos loca-

${ }^{7}$ Diario Oficial, Suplemento del núm. 30 del t. Lv, 7 de agosto de 1929, 1-14. 
les y regionales preexistentes a la par de las obras hidráulicas (decenas de presas porfiristas paulatinamente fueron anegadas, otras abandonadas, aunque no podemos negar que muchas siguen funcionando). Si bien se establecían criterios para fijar las asignaciones de aguas a los ejidos conforme a la superficie regable, al clima, a los cultivos o a las pérdidas de conducción, en la realidad eran los factores de índole político los que podían influir (promover, avanzar o detener) en el reparto. Por otra parte, la redistribución del agua significaba también un nuevo reparto del poder, este aspecto se reflejaría a la hora de elegir a las juntas directivas de las Asociaciones de Usuarios contempladas en las leyes de aguas de 1929 y de 1934, así como en quienes otorgaban y podían usufructuar el agua. También se presentó un cambio en los paisajes ambientales, al darle prioridad a ciertos terrenos y abandonar otros que contaban con el preciado líquido, lo que aunado al tipo de cultivos (p.e. huertas de naranja) nos marca una serie de aspectos que no solamente podrían ser registrados en los que los ejidos pudieron utilizar poco los sistemas de riego que "heredaron" a través de la intervención estatal.

\section{EL ESPACIO RIOVERDENSE}

El espacio que en este artículo se denomina "Rioverde" es una serie de valles que se localiza en la denominada zona media de San Luis Potosí, por lo que hablaremos del valle rioverdense. Esta planicie se extiende 60 kilómetros de norte a sur y 35 kilómetros de este a oeste y se encuentra comprendida entre diversas elevaciones: hacia el oeste se localiza el sistema de sierras de La Noria, Cieneguilla, San Diego y El Jabalí; por el norte se hallan los cerros Veteado y de Angostura; al sur se ubica el cerro de La Campana y la Sierra de La Lágrima, que son derivaciones de la Sierra Gorda; y por el este el límite es el cordón de San Francisco y La Boquilla, que consiste en pequeñas serranías. La altitud media del valle es de mil metros sobre el nivel del mar, pero presenta una ligera inclinación hacia el sureste, la cual se acentúa en el sur, mientras que en el norte es prácticamente nula.

El relieve tiene un papel importante en relación con la disponibilidad de agua, pues las elevaciones que rodean el valle permiten la 
disposición de agua en la parte baja gracias a los escurrimientos torrenciales durante la temporada de lluvias. Gracias a ellos y a los manantiales existentes es posible el riego, aspecto esencial para el desarrollo de la agricultura en virtud del clima predominante, el que, durante la primavera y el verano, puede ascender hasta $42^{\circ} \mathrm{C}$. Así, la irrigación es necesaria para alcanzar rendimientos adecuados en la agricultura y gracias a las elevaciones que circundan a la zona se puede disponer de líquido para llevarla a cabo. Sin embargo, la calidad de los suelos, la inclinación del terreno y la distribución de las fuentes de agua condicionaron el uso del agua en el valle, hasta que no se pudieran realizar obras hidráulicas que permitieran elevar el líquido a los campos agrícolas.

Gran parte del noroeste es ocupado por la Sierra de la Noria, que se extiende casi desde la margen izquierda del río Verde hacia el norte. En el noroeste de Rioverde, las posibilidades productivas son importantes, debido a los feozem, terrenos planos con posibilidades de ser irrigados con el agua de las escorrentías de la Sierra de La Noria. En el norte los suelos contienen altas cantidades de sales, independientemente del tipo que sean, y en la mayoría de los casos su uso agrícola se encuentra restringido a la posibilidad de contar con riego. Hasta los 1920 fue posible contar con agua en el noroeste. Sin embargo, el empleo de estos suelos para la ganadería era muy factible, principalmente para ovejas y cabras.

En el norte de Rioverde, las posibilidades para la agricultura eran más limitadas, en virtud de que una extensa superficie es inutilizable debido a la excesiva salinidad. Sólo en algunas porciones, especialmente en el noroeste, era posible cultivar caña de azúcar, algodón, maíz y frijol. Hay que subrayar que en gran parte del norte de Rioverde la ganadería extensiva era la principal actividad, gracias a los pastizales que cubren los suelos salinos. ${ }^{8}$ En el sur, entre la margen

\footnotetext{
${ }^{8}$ Varios documentos localizados en el Archivo Histórico del Agua, que contienen estudios realizados sobre las corrientes y manantiales de Rioverde, sugieren que en algún horizonte geológico toda esta zona estuvo cubierta por el mar, ya que las rocas que se localizan debajo de los suelos se encuentran formadas por sedimentos marinos. Éstas se distinguen por que se trata de rocas permeables, donde es frecuente encontrar grandes cavernas. AHA, Aprovechamientos Superficiales, c. 1623, exp. 23327.
} 
derecha del río Verde y el inicio de las estribaciones de la Sierra Gorda, la salinidad disminuye considerablemente. Ello se debe a la ligera pendiente que existe hacia el sureste, la cual permite un drenaje más adecuado. Los problemas de sales en esta porción de Rioverde se localizan sólo en pequeñas depresiones que no cuentan con un buen drenaje.

Las fuentes de agua superficiales en Rioverde consisten en una serie de manantiales que afloran en el valle, así como en los ríos de carácter intermitente y permanente que se forman en las sierras que lo rodean y confluyen en él. El más relevante es el de la Media Luna que se localiza en el sureste del valle, produce alrededor de cuatro metros cúbicos de agua por segundo y dio vida a una de las zonas irrigadas más importantes en Rioverde desde el siglo Xvir. Otros manantiales menores conforman tres grupos: el primero de ellos se localiza en el sureste y se integra por los manantiales Charco Azul, Charco Sentado, El Sabinito, El Álamo, Agua Sonadora, La Rosa, El Carrizalito y Palma Larga. El segundo grupo está conformado por Los Peroles, Las Sabanas, El Sabino y Poza Azul, también ubicado en el sureste. El tercero, situado en el norte, es integrado por El Baño, Santa Rosa, Mojarras, San Bartolo y La Lagunita.

La mayoría de los manantiales se concentra en el sureste. Ahí tan sólo el de la Media Luna ofrecía posibilidades de irrigar una superficie amplia. Sin embargo, un factor que ocasionaba problemas para un aprovechamiento pleno del agua en esa zona eran las grietas y cavernas que se forman en las calizas, las cuales actúan como resumideros. En este sentido, el agua se mantiene en la superficie mientras se encuentre sobre el travertino, pero al entrar en la formación caliza los cursos de agua desaparecen. ${ }^{9}$ Por ejemplo, en un punto ubicado al sureste de la Media Luna se formaba una caverna por donde fluía el agua y daba lugar a una corriente subterránea llamada "río Enterrado". Ésta resurgía en un punto más adelante y en la misma dirección, donde se utilizaba para la irrigación. ${ }^{10}$

${ }^{9}$ AHA, Consultivo Técnico, c. 586, exp. 5501.

${ }^{10}$ Cabe señalar que estas condiciones se han modificado a partir de la creación del distrito de riego 049 de Rioverde. 
Un factor más que dificultó el uso de los manantiales, especialmente el de la Media Luna, es la pendiente del valle, que si bien, ésta no es muy pronunciada en todo Rioverde, es más perceptible y tiende hacia el sureste. Así, las aguas del manantial sólo podían regar la zona ubicada hacia el sureste, las que se podían conducir por medio de gravedad. En cambio, hacia el poniente no era posible conducir el líquido de la misma manera porque las tierras se localizaban en un nivel más alto. Ese factor físico determinó que sólo una parte del manantial fuera aprovechada, mientras que para regar las tierras del suroeste se realizó el represamiento de las aguas torrenciales. Dichas aguas confluyen en el valle, provenientes de las sierras que lo rodean. Algunos de los arroyos más sobresalientes eran el de Canoas, La Loma y San Diego.

Una dificultad más para el aprovechamiento del agua del río para la irrigación se debió a la diferencia de altitud entre su cauce y el valle. Hasta las primeras décadas del siglo xx esto representaba un obstáculo difícil de salvar. Así, en un informe de 1922 se señalaba que el descenso del valle al lecho del río no era uniforme pues la pendiente era brusca, formando un pequeño acantilado, y luego había un escalón donde se constituían vegas que eran inundadas y enlamadas durante las avenidas máximas. ${ }^{11}$ Sin embargo, la anchura de éstas variaba entre 0 y 300 metros, de forma que se alcanzaba una superficie de 46 hectáreas en las que era posible utilizar el agua del río. ${ }^{12}$

Finalmente, la disponibilidad de agua en el norte de Rioverde se debe a los escurrimientos que provienen del sistema de sierras de la Noria, los cuales forman dos corrientes permanentes que fueron esenciales para la práctica de la irrigación desde mediados del siglo xVIII. Se trata del río Choy o San Tiburcio, que se forma a partir de los escurrimientos en la zona de Huaxcamá y corre hacia el sureste hasta confluir con el río Verde, y del manantial El Nacimiento. Como veremos, a partir de ambas corrientes se construyeron obras hidráulicas que permitieron regar parte de las tierras del noroeste pertenecientes a la hacienda de La Angostura.

${ }^{11}$ AHA, Aprovechamientos Superficiales, c. 1291, exp. 17657.

${ }^{12}$ En 1926 las 46 hectáreas se dividían entre 72 pequeńos propietarios. AHA, Aprovechamientos Superficiales, c. 1349, exp. 18390 y c. 1291, exp. 17657. 


\section{LAS UnidAdes PRODUCtivas DE Rioverde}

Durante 1930, los valles rioverdenses estaban ocupados por propiedades privadas de diferentes tamaños, producción y ocupación de nichos ecológicos, existían entre 18 y 20 aproximadamente. Si bien también había pequeñas propiedades, el peso de éstas en la estructura agraria era mínimo. Las haciendas que más se destacaban por su superficie y por su importancia económica eran La Angostura, Ojo de Agua de Solano, Amoladeras, San José del Tapanco, El Jabalí, La Boquilla, Cieneguilla, Diego Ruiz y San Diego. De ellas, La Angostura sobresalía por sus dimensiones, cuya superficie era de aproximadamente 180 mil hectáreas en la década de 1890. Esta hacienda se extendía sobre gran parte de las tierras del norte del valle. ${ }^{13}$ Las otras dos haciendas que compartían la porción norte eran Diego Ruiz (11,853 hectáreas) y La Boquilla. La primera de ellas se localizaba al pie de la Sierra de La Noria, mientras que la segunda se encontraba hacia la sierritas de La Boquilla, que limitaban al valle de Rioverde por el oriente. Aunque con una superficie notablemente menor a la de La Angostura, La Boquilla era otra de las haciendas que destacaba por sus 40,497 hectáreas. ${ }^{14}$ En el sur, El Jabalí era la hacienda de mayor relevancia con unas 45,249 hectáreas. ${ }^{15} \mathrm{~A}$ principios de la década de 1920, San Diego medía sólo 5,364 hectáreas (Cabrera Ypińa y Cabrera Ypiña 1989, 146-147), sin embargo, era una de las más productivas del sur de Rioverde. Otra de las haciendas importantes era Ojo de Agua de Solano, que tenía una superficie de más de 20 mil hectáreas y una fracción considerable de tierras inmediatas a la margen izquierda del río Verde (Escobar Ohmstede 2009, 19-99; Escobar Ohmstede y Gutiérrez 2008, 157-180).

La mayoría de las haciendas se extendían sobre terrenos bajos correspondientes al valle, pero también sobre partes altas, lo que conduce a pensar en una lógica de control de una diversidad de recursos naturales (agua, bosques, tierras). Por ejemplo, las haciendas

${ }^{13}$ AHESLP, Comisión Agraria Mixta (en adelante CAM), Rioverde, La Angostura, dotación de tierras, 1929.

${ }^{14}$ AHESLP, CAM, Rioverde, Acequia Salada, dotación de tierras, 1936.

${ }^{15}$ CCJSLP, Juzgado $1^{\circ}$ de Distrito, Amparo, exp. 183/1928. 
MAPA I. El valle de Rioverde

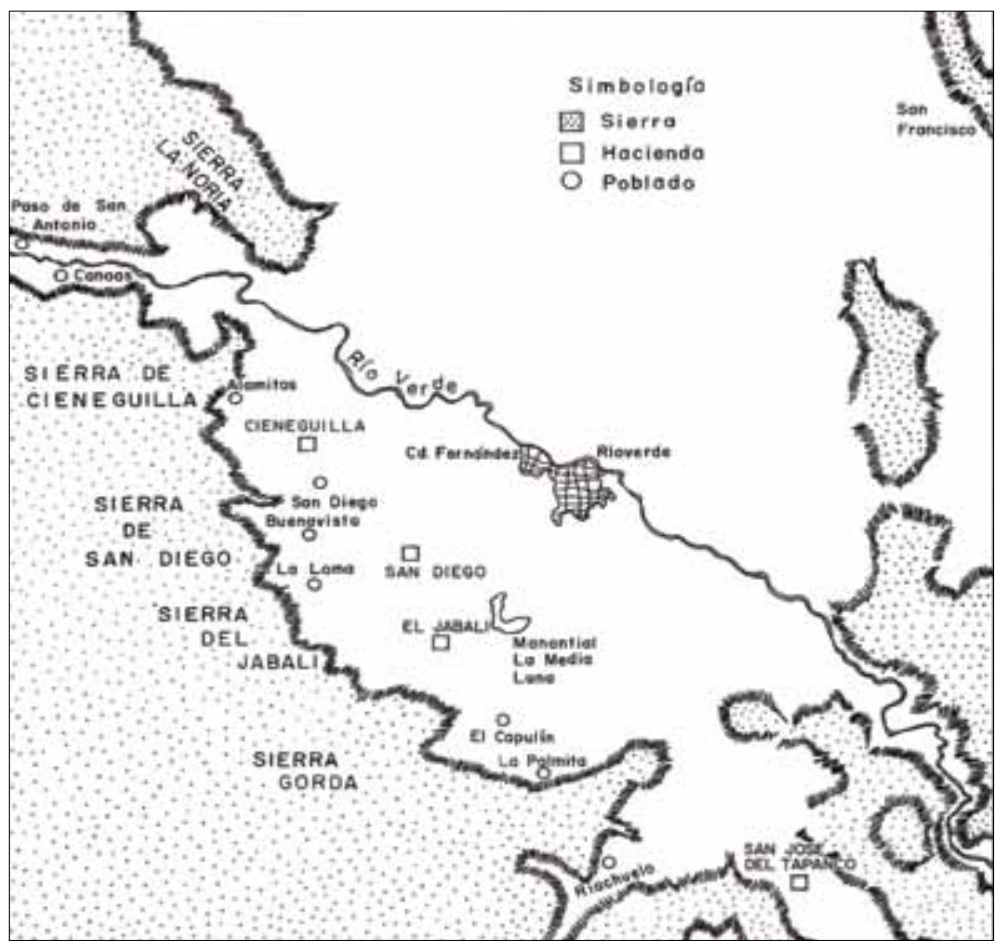

Adaptación de Charcos Salazar, 2002.

del sur de Rioverde, como El Jabalí, San Diego y Cieneguillas, comprendían terrenos del valle, pero también partes de las sierras de El Jabalí y San Diego. Lo mismo se puede asegurar para el caso de la hacienda de La Boquilla y de Diego Ruiz, situadas en el norte de Rioverde, las cuales comprendían lo mismo tierras de agostadero y cultivables en la parte baja, que cerriles en la Sierra de La Boquilla y en el sistema de Sierras de La Noria, respectivamente.

En el poniente de Rioverde, antes de entrar al valle hay una angosta franja de terrenos planos que rodean al río Verde, tierras que eran dominadas por una serie de haciendas de menores dimensiones que las que se han mencionado en los párrafos anteriores. Entre ellas se encontraban San José de Gallinas, Paso de San Antonio, Canoas, 
Cañada Grande, La Noria y Tecomates. Todas ellas se integraban también por pequeńas porciones de terrenos bajos y cerriles.

A finales del siglo XIX, esas propiedades pertenecían a miembros de las distintas ramas de la descendencia de Felipe Barragán, como los Díez Gutiérrez, los Arguinzoniz, los Escontría y los Verástegui. Todas estas familias estaban emparentadas entre sí y, cabe destacar, formaban parte del grupo de poder potosino e incluso eran miembros prominentes de los gobiernos estatal y federal (Falcón 1984, 24 y 1988, 89-112; González 1902 [2002], 79). Así, la hacienda de San Diego contaba con 27,858 hectáreas, pero en 1849 sufrió una primera segregación, a raíz de la cual se desprendieron de ella la "hacienda" de San José de Gallinas y los ranchos de Tecomates, La Tapona y Acequia Salada (posteriormente recibió el nombre de La Boquilla). Más tarde, en 1901, San Diego sufrió una segunda división, también por herencia, pues fue separada de ella la fracción de Cieneguilla.

No obstante, conviene señalar que para los años posteriores a la revolución de 1910, la mayor parte de las tierras que originalmente habían pertenecido a San Diego continuaban en manos de distintas ramas de la familia Verástegui. Así, la propiedad que conservó el nombre de San Diego estaba en manos de la Sociedad Verástegui Hermanas, mientras que Cieneguilla era propiedad de Teresa Verástegui, hermana de las anteriores. Por otra parte, Tecomates pertenecía a Ángela García Verástegui y Acequia Salada se había convertido en una estancia de la hacienda de La Boquilla, cuyo propietario era Casimiro García Verástegui (Cabrera Ypińa y Cabrera Ypiña 1989, 79).

Para completar el predominio de la familia Verástegui en el sur de Rioverde hay que decir que la hacienda del Jabalí también pertenecía a una de sus ramas. Hacia 1920, esta hacienda contaba con 45 mil hectáreas y era la más grande del sur de Rioverde. Sin embargo, hasta la década de 1870 era más extensa aún, ya que ocupaba la mayor parte de los terrenos planos del sur de Rioverde, amén de que también se extendía sobre una porción considerable de las Sierras de La Lágrima, La Campana y El Jabalí. Con todo, igual que San Diego, sufrió un proceso de fraccionamiento. De hecho, en 1834, se desprendió de ella la fracción de San José del Tapanco por 
asuntos de herencia constituyéndose ésta en una hacienda independiente. ${ }^{16}$ En 1906, Franco Verástegui, en cuyo poder quedó la hacienda de El Jabalí, vendió la citada hacienda a Pablo Escandón y Barrón, un integrante de la elite morelense porfiriana (Cabrera Ypiña y Cabrera Ypińa 1989, 120-121). Se puede decir entonces que San Diego y El Jabalí fueron las dos propiedades de las cuales se desprendieron la mayoría de las haciendas que existían en el sur de Rioverde al iniciar el siglo xx. También es preciso enfatizar que El Jabalí ocupaba la mayor proporción de terrenos cultivables en esta zona, pues se extendía sobre la parte más ancha de tierras entre el río Verde y las estribaciones de la Sierra Gorda, además que controlaba las aguas de la Media Luna.

\section{CONFlictos, Negociaciones y ACUERDOS ENTRE LOS GRUPOS DE PODER POR EL AGUA}

La evidencia más temprana de la práctica de la irrigación data del siglo XVII y concierne a la construcción de una acequia que regaba las tierras de los indígenas de Rioverde, la cual se desprendía del manantial de la Media Luna. Posteriormente, en 1731, los pobladores de la villa de Santa Elena obtuvieron una merced de agua del mismo manantial, de manera que construyeron una acequia más. Ambas eran de tierra y a cielo abierto. Ya a mediados del siglo XVIII el propietario de la hacienda de Nuestra Señora del Rosario, alias El Jabalí, inició el cultivo de caña de azúcar, así que para regar sus cañaverales excavó dos canales más que derivaban agua del citado manantial, lo cual paulatinamente creó problemas que duraron varias decenas de años. ${ }^{17}$

Vale la pena recordar menciones realizadas anteriormente. La primera de ellas es la inclinación del terreno en el sur de Rioverde en

${ }^{16}$ CCJSLP, Juzgado $1^{\circ}$ de Distrito, Civil, exp. 40/1884.

${ }^{17}$ AGN, Tierras, vol. 946, exp. 2, fs. 1-90 y vol. 1154, exp. 3, fs. 7-71. Sobre el curso y desenlace de los conflictos entre 1894 y 1902 entre Ciudad Fernández, el municipio de Rioverde y la hacienda, véanse los documentos que se localizan en el rollo 52 de la BINAH, Microfilms, serie San Luis Potosí, así como Escobar Ohmstede (2005, 157-186) y Berumen (2005 y 2008, I, 103-123). 
dirección al sureste. Ésta influyó en que el agua no se pudiera conducir por medio de gravedad hacia las tierras ubicadas al poniente del manantial. De hecho, las tierras más altas de la villa de Santa Elena, más tarde Ciudad Fernández, no se podían regar a menos que se emplearan embalses para elevar el nivel del agua lo suficiente a manera de distribuirlas después por gravedad. Tomando en consideración el factor de la pendiente, las tierras del poblado de Rioverde contaban con ventajas para el regadío, pues las acequias secundarias que se desprendían de la principal seguían la pendiente natural del terreno. Sólo algunos de los terrenos ubicados al poniente del poblado debían regarse a través de la acequia de Ciudad Fernández puesto que no era posible conducir el agua a partir de la acequia del propio poblado. ${ }^{18}$

En el caso de la hacienda del Jabalí, varios aspectos limitaron un uso más intensivo del agua de la Media Luna. Por supuesto que uno de ellos era la pendiente del terreno. Esto es, no se podía conducir el agua a las tierras situadas al poniente del manantial por medio de gravedad dado que su altitud era ligeramente superior. Por otra parte, una porción considerable de las tierras aledañas al manantial eran pantanosas, de manera que ahí el problema más bien era el exceso de líquido, por ello, en la última década del siglo xIx, los propietarios de la hacienda emprendieron un proyecto de drenaje de una parte de la superficie cenagosa. De esta manera, el mayor problema del Jabalí era el control de la abundancia de agua. Las tierras irrigadas eran las cercanas a la sierra del Jabalí y del Capulín, que eran derivaciones de la Sierra Gorda. Precisamente la presencia de estas sierras significó una limitante para la expansión del riego del Jabalí en su zona sureste, a donde sí era posible conducir el agua por medio de gravedad. Debido a estos factores, fue la que menos agua obtuvo en la reglamentación de la distribución realizada a finales del siglo XIX, aspecto

${ }^{18}$ BINAH, Serie San Luis Potosí, rollo 52. Aquí se especifica que las tierras del barrio de San Rafael, del municipio de Rioverde eran regadas por la acequia de Ciudad Fernández. También se indica que todos los viernes se cerraban todas las compuertas con el fin de hacer subir el nivel del agua y que llegara a las compuertas altas. En el caso de Ciudad Fernández también se acudía a poner obstáculos en la acequia con el fin de rebalsar el agua y subirla a los terrenos altos. AHA, Aprovechamientos Superficiales, c. 1245, exp. 17165, f. 155. 
que llama la atención si se considera que la fuente acuífera se localizaba dentro de esa propiedad. Así, en la reglamentación mencionada, se le asignaron a Rioverde 1,846 litros por segundo de los 4,611. A Ciudad Fernández se le señalaron 990 litros, mientras que a la hacienda sólo se le asignaron 921 litros. ${ }^{19}$ Además, de los 4,611 litros que producía el manantial, casi 700 se dejaban correr por el río Enterrado, que se formaba gracias a la caverna que existía entre las calizas y que corría hacia el extremo sureste del valle.

Los propietarios de El Jabalí acudieron a otra alternativa con el propósito de regar las tierras ubicadas al poniente de la Media Luna: el represamiento de las aguas torrenciales. No ha sido posible identificar el momento en que se construyó la presa del Jabalí, pero ya aparece en un plano de la hacienda elaborado en 1881 y copiado en 1895 y 1902 con motivo del deslinde de la misma. El vaso captaba las avenidas de numerosos arroyos intermitentes que provenían de las sierras del sur de la hacienda. El más importante de ellos era el arroyo de La Loma. Las aguas almacenadas durante la época de lluvias se empleaban en los riegos durante la temporada de secas. ${ }^{20}$

En la hacienda de San Diego se recurrió al almacenamiento de las aguas permanentes de los manantiales del Nacimiento. Si bien no he localizado la fecha precisa de la construcción de la presa y del acueducto que conducía las aguas de los manantiales de El Nacimiento hasta el casco de la hacienda. El acueducto corría por la margen izquierda del río San Diego y se pasaba el agua a la margen derecha por medio de un puente canal. El agua llegaba hasta el casco de la hacienda, donde irrigaba parte de las tierras, se utilizaba en usos domésticos y en la producción de fuerza motriz para la molienda de la cańa de azúcar. ${ }^{21}$

Asimismo, en San Diego también se realizó el almacenamiento de las aguas torrenciales de los arroyos que bajaban de la Sierra de

${ }^{19}$ BINAH, Microfilms, Serie San Luis Potosí, rollo 52; AHA, Aprovechamientos Superficiales, c. 1245, exp. 17165. También Sandré y Sánchez 2001, 90-94, 186-194, 234240.

${ }^{20} \mathrm{La}$ información sobre todos estos escurrimientos intermitentes que concurrían a la presa de El Jabalí se encuentra en CCJSLP, Juzgado $1^{\circ}$ de Distrito, Amparo, exp. 220/1928.

${ }^{21}$ AHA, Aprovechamientos Superficiales, c. 2014, exp. 30302, fs. 7-13. 
San Diego, entre ellos el de la Víbora, el de las Palomas y el de Alamitos. La reunión de todos esos arroyos tomaba el nombre de río San Diego. No puedo asegurar si la construcción de la presa de San Diego formó parte de la etapa de edificación del acueducto de los manantiales del Nacimiento, pero se puede afirmar que a fines del siglo xix ésta captaba no sólo las aguas de los manantiales mencionados, sino también las aguas mansas y torrenciales del río San Diego, por lo que posiblemente sean dos obras diferentes y con finalidades específicas. Para lograrlo se había construido una presa derivadora sobre el río y un canal de tierra que conducía el agua al vaso de almacenamiento, ubicado en la margen derecha. Este último se formaba con "dos cortinas". La más importante de ellas tenía diez metros de altura como máximo, dos metros de ancho en su corona y 200 metros de longitud. Su capacidad aproximada era de cuatro millones de metros cúbicos. ${ }^{22}$

Este vaso de almacenamiento posibilitaba el riego de casi 500 hectáreas, pero las tierras irrigables de San Diego se calculaban en unas 1,165 , de manera que en vísperas de la Revolución las hermanas Verástegui habían concebido planes de construir una nueva obra hidráulica que aparentemente no llegó a concretarse (Bazant 1975, 158; Amerlinck 1980, 183). Aunque también podemos considerar que debido al nivel friático del valle rioverdense no solamente se pretendía usar el riego por gravedad, sino también a través de bimbaletes, de los cuáles se han encontrado datos para Guanajuato, San Luis Potosí y Zacatecas. ${ }^{23}$

22 AHA, Aprovechamientos Superficiales, c. 2014, exp. 30302, fs. 7-13; AHESLP, CAM, San Diego, Rioverde, dotación, 1924. Es posible que la presa haya sido construida en la primera mitad del siglo xIx. Todavía es posible observar la cortina de la presa, ya que se encuentra en buen estado de conservación. Recorrido de campo, febrero de 2005, octubre 2006 y noviembre 2007.

${ }^{23}$ La capacidad de elevación de un bimbalete es variable, de dos a siete metros, así como el total de agua que se puede elevar por minuto (30, 50, 120 y 145 litros) de un pozo que puede tener dos metros de ancho. Para 1891, William Henry Jackson registró bimbaletes para riego y para sacar agua de pozos en Rioverde. Una de las fotografías muestra un "ejército" de bimbaletes en un terreno plano. En primer término se muestra una persona moviendo un bimbalete puesto sobre un pozo recién excavado, así como un canal de tierra enramado por donde recorría el agua para regar las plantas de algodón y hortalizas. BMNAH, Fondo Texeidor, núm. 460410. En 1980 se menciona la existencia de 
En el norte de Rioverde la hacienda de La Angostura prácticamente logró el monopolio de las corrientes de agua más importantes, las cuales se formaban a partir de los escurrimientos del sistema de Sierras de La Noria, en el poniente de la hacienda. Estos escurrimientos formaban dos corrientes importantes: el río Choy o San Tiburcio y el manantial El Nacimiento. Vale la pena señalar que en este caso se trataba de aguas permanentes y no torrenciales, como era el caso de las propiedades privadas antes mencionadas en el sur, en las que había sido necesaria la construcción de presas de almacenamiento de las aguas pluviales. Es decir, se trataba de una forma de control del agua distinta a la que se ha señalado para el caso de aquellas propiedades. Algunos documentos sugieren que por lo menos desde la segunda mitad del siglo XvIII se comenzaron a construir obras hidráulicas en La Angostura. ${ }^{24}$

Si bien son escasos los datos sobre la edificación de la infraestructura hidráulica, además de las trojes dispersas por diversos puntos de La Angostura, se puede asegurar que gran parte de ella se construyó en el curso del siglo xIx y consistió básicamente en canales para derivar las aguas del río Choy o San Tiburcio (Escobar Ohmstede 2011, 287). Pareciese que los Espinosa y Cuevas también emplearon el bombeo con el fin de aumentar la superficie irrigada a finales del siglo XIX o principios del siglo Xx. De hecho, aún se puede ver la casa que albergaba las bombas junto a un manantial en las cercanías de San Bartolo.

Finalmente, no estaría completo el panorama sobre el proceso de control de las aguas en Rioverde si no se hiciera alusión a los esfuerzos que por lo menos desde mediados del siglo xix se realizaron con el propósito de aprovechar las aguas torrenciales del río Verde. Como se ha mencionado, hasta el punto llamado Ojo de Agua de

bimbaletes en la Planicie del río La Presa-Justiano-Bocas o valle de la Parada, Cañada del río Mexquitic y en la Cañada del río Las Enramadas-Santa María. Véase, Fortanelli (1997, I, 343-344). Sobre este tipo de sistema de riego, véase Palerm (2002, III, 325-340).

${ }^{24}$ Existe un tramo aun del acueducto con algunas "tazas" que permitían que el agua no llegara a una mayor velocidad; de éstas se encuentran restos entre el cerro y el acueducto, lo que hace suponer que antes de que el agua llegara a éste se trasladaba el agua por algún canal. La obra hidráulica terminaba en un pequeño molino cercano a la acequia que provenía de El Nacimiento. 
Solano, el río Verde era una corriente intermitente que en la época de lluvias podía conducir un caudal considerable, pero cuyas avenidas no excedían de 20 días por año. Estas aguas corrían sin ser utilizadas a pesar de que las tierras aledañas al río eran de buena calidad. Se trataba de buenas tierras que, por carecer de riego, sólo se destinaban al cultivo de maíz. La mayoría de ellas formaban parte de la hacienda de Ojo de Agua de Solano. Otras pertenecían a la hacienda de Gallinas y una pequeña fracción a la hacienda de La Noria. Con todo, los terrenos de Ojo de Agua de Solano eran los mejor ubicados, ya que Gallinas y La Noria se situaban en el estrecho paso que se formaba entre las Sierras de La Noria y La Sierra de Cieneguilla, de manera que sus superficies planas eran muy reducidas. En cambio, las tierras de Ojo de Agua de Solano se localizaban justamente donde iniciaba el valle.

En 1891 se realizaron los primeros esfuerzos concretos para retener las aguas torrenciales del río bajo los auspicios de Franco Verástegui, dueño de la hacienda El Jabalí y sobrino de Paulo Verástegui. En ese año Franco, también propietario de Ojo de Agua de Solano, llegó a un acuerdo con el dueño de La Noria para abrir una toma en sus terrenos. Asimismo, estableció un contrato con varios pequeños propietarios para establecer una servidumbre a fin de conducir el agua a través de sus propiedades y llevarla hasta la hacienda. El canal tenía un ancho de seis metros, lo que nos da una idea sobre el caudal que podía conducir el río Verde durante la temporada de lluvias. ${ }^{25}$ La toma se abrió unos siete kilómetros arriba del manantial de Ojo de Agua de Solano y regaba aproximadamente 119 hectáreas de pequeñas propiedades antes de llegar a la hacienda. En 1902, Franco Verástegui vendió la propiedad a Carlos Fernández Galán, quien continuó con los planes de extender la irrigación. Para ello construyó una presa más aguas abajo del manantial, a partir del cual el río

${ }^{25}$ AHA, Aprovechamientos Superficiales, c. 145, exp. 3389, fs. 5-6. A mediados de 1892 se elaboró un plano con el fin de mostrar los posibles acuerdos con varios copropietarios de la hacienda, así como la ubicación de la noria y del dique principal. Inclusive se ubica un alambique que se beneficiaría con las obras de construcción que se encontraba frente al "bordo" de los hermanos Torres. AHA, Aprovechamientos Superficiales, c. 3493, exp. 48013. 
Verde comenzaba a ser permanente. ${ }^{26}$ Con esta obra Fernández Galán pudo aprovechar las aguas mansas del río. En un documento se especificaba que una de las presas podría almacenar $1,500,000 \mathrm{~m}^{3} \mathrm{y}$ la otra 10,000,000 $\mathrm{m}^{3}$, sin duda, eran obras de gran envergadura (Castañeda, Escobar Ohmstede y Andrade, comps., 2005, 107117). Sin embargo, Fernández Galán cifró sus principales expectativas en un proyecto de mayor importancia, pues planeaba regar casi la totalidad de las tierras de la hacienda, que ascendía a más de 20 mil hectáreas. Con el fin de alcanzar este objetivo, concibió la construcción de una presa que almacenaría las aguas torrenciales del río Verde en el punto llamado Cerro del Colimote, ubicado en terrenos de la hacienda de Gallinas. De hecho, en 1910 compró a Cipriano Cobo, dueño de esta hacienda, el terreno necesario para construir la citada presa, así como uno o dos canales con el fin de llevar el agua a los terrenos altos de la hacienda de Ojo de Agua de Solano. Sin embargo, la llegada de la Revolución impidió que Fernández Galán pudiera concretar su plan, pero si ver como su propiedad perdía la infraestructura frente a la colonia militar creada por Saturnino Cedillo y la Congregación La Reforma, lo que a su vez marcó el paulatino desmembramiento de la hacienda, además de la destrucción física de la casa principal. ${ }^{27}$

\section{Llega la ReVOlución a los VALles}

En el reparto agrario de Rioverde es posible distinguir dos momentos con base en el número de acciones agrarias: el primero, comprende de 1924 a 1947, mientras que el segundo va de 1951 a 1964. Durante el primero hemos podido identificar casi 101 acciones agrarias, incluyendo dotaciones y ampliaciones. ${ }^{28} \mathrm{Si}$ bien, después de 1947 se registraron varias solicitudes más, éstas fueron resueltas de manera negativa, por lo que casi podemos considerar es que en ese año se alcanzó el límite de la expansión de los ejidos, y de ahí la

\footnotetext{
${ }^{26}$ AHA, Aprovechamientos Superficiales, c. 145, exp. 3389, fs. 87-88.

${ }^{27}$ AHA, Aprovechamientos Superficiales, c. 251, exp. 17203, fs. 6-6v y 11-11v.

${ }^{28}$ Werner (1988, II, 160-161) considera que entre 1915 y 1935 hubo 782 solicitudes de tierra en San Luis Potosí.
} 
importancia de distinguir ambos periodos. Por otra parte, durante el segundo momento se llevaron a cabo 25 acciones agrarias relacionadas sólo con agua. De ellas, 12 fueron accesiones que consistieron en formalizar la entrega del agua correspondiente a las tierras clasificadas como de riego dentro de una dotación o ampliación de tierras, básicamente a aquellos que habían sido peones de las propiedades privadas, ya que en el primer momento, muchos de los solicitantes eran los trabajadores de las fábricas, arrendatarios o medieros. Las otras 13 acciones relativas a aguas fueron dotaciones, pero de estas últimas sólo ocho se resolvieron afirmativamente. Las dotaciones de agua que tuvieron lugar durante estos años implicaron la expansión de las tierras de riego de los ejidos con base en aguas superficiales, no así las accesiones cuyos volúmenes de agua ya eran usados por los respectivos ejidos.

La suma de las tierras afectadas para la formación de los ejidos vía dotación y ampliación entre 1924 y 1947 ascendió a aproximadamente 189,291 hectáreas. ${ }^{29}$ De ellas 5, 667 eran de riego, las cuales representaban $2.9 \%$ de la superficie total dotada a los ejidos. De las 101 acciones agrarias registradas, 26 contenían tierras de riego y humedad. Podría concluirse que fueron escasas las tierras de riego traspasadas a los ejidos, sin embargo, esa cifra adquiere otra dimensión si se toma en cuenta que representaba alrededor de $97 \%$ de todas las tierras de riego que pertenecían a las haciendas de la zona, las cuales fueron rápidamente solicitadas por arrendatarios y medieros. En otras palabras, casi todas las tierras de riego de éstas pasaron al control de los ejidos. ${ }^{30}$

${ }^{29}$ Consideramos esta cifra sólo como una aproximación en virtud de que en varios casos no fue posible obtener la superficie considerada en la resolución presidencial, así que sólo se contabilizó la asentada en la resolución provisional y podía haber variaciones entre ambas.

${ }^{30} \mathrm{El}$ porcentaje se ha obtenido tomando en consideración los datos aportados en el estudio realizado por la Corresponsalía de la Novena Zona Agrícola de San Luis Potosí en 1947 en el cual aparece que las tierras irrigadas en Rioverde ascendían a un total de 9,315 hectáreas, de las cuales 3,500 correspondían a las pequeńas propiedades de Rioverde y Ciudad Fernández, de manera que se concluye que las 5,815 restantes pertenecían a las haciendas. Así, las 5,667 hectáreas de riego que hemos contabilizado en las dotaciones y ampliaciones de tierras representaban $97 \%$ de esas 5,815 hectáreas. El estudio se puede consultar en AGN, Presidentes, Miguel Alemán Valdés, exp. 404.2/188. 
Así, entre 1924 y 1947, el reparto afectó principalmente a las propiedades del sur y a las ubicadas en las márgenes del río Verde, en especial las tres haciendas más importantes del sur, esto es, El Jabalí, San Diego y Cieneguillas. Sólo una vez se afectó a la de San José del Tapanco, también ubicada en el sur. Eventualmente se pueden identificar otras unidades productivas que fueron repartidas como Tecomates, Canoas y Labor Vieja, así como otras situadas en las márgenes del río Verde, como La Boquilla, Ojo de Agua de Solano y La Noria. Durante estos primeros años sólo se realizó una afectación a La Angostura, que se localizaba en el norte.

La explicación al temprano reparto de las tierras agrícolas productivas en Rioverde no puede separarse de las pugnas existentes en la vida política estatal y nacional. Así pues, los autores que han abordado el tema del reparto agrario en San Luis Potosí, incluido Rioverde, han manejado como momentos de particular intensidad los ańos de 1924-1925, 1927-1929 y 1937-1939, los que corresponden a coyunturas políticas de índole nacional y estatal, las cuales tuvieron que ver con diferentes etapas de un proceso que tendía al fortalecimiento de la institución presidencial (Falcón 1984 y 1988a; Ankerson 1994; Lerner 1986, 323-362 y 1987, 661-697; Werner 1988, II, 149-173).

Durante los tres primeros años de la década de 1920 no se repartieron tierras, lo que puede atribuirse a las ideas del gobernador Rafael Nieto con respecto a la cuestión agraria. Éstas se acercaban mucho a las del presidente Álvaro Obregón. Así pues, para Nieto la reforma agraria consistía en fraccionar las grandes propiedades con el fin de crear una clase media de pequeńos propietarios, lo que no implicaba la expropiación de las tierras y aguas, ya que el proceso debía darse mediante la venta de las fracciones en que se dividirían las grandes propiedades. Los planteamientos de Nieto fueron plasmados en la ley agraria estatal de julio de 1921, en cuyos artículos se establecieron también las superficies máximas de las propiedades atendiendo a la calidad de las tierras y a su disposición de agua. En atención a ello se distinguieron tres zonas en la entidad: el altiplano o zona occidental, la zona central o media y la zona oriental. En el caso de la primera, más árida, las propiedades no debían superar las 
cuatro mil hectáreas; en la zona central o zona media la superficie máxima se fijó en tres mil hectáreas; y, por último, en la región oriental no podrían exceder las dos mil hectáreas.

El plazo para fraccionar las propiedades con superficies superiores a las marcadas para cada zona fue de un año. En otra de las cláusulas de la misma ley se exceptuaba de la obligación de segmentar a los propietarios de fincas que necesitaran de una superficie mayor para el sostenimiento de una industria. La obtención de la exención requería que los interesados la solicitaran explícitamente, en cuyo caso se debía expedir un decreto especial, aspecto que utilizó de manera muy adecuada Pablo Escandón y Barrón, propietario de la hacienda de El Jabalí, cuando obtuvo del congreso del estado uno (el número 81 con fecha del 7 de octubre de 1922) que lo exceptuaba de dividir 7,800 hectáreas en vista de que formaba parte de una unidad industrial que producía azúcar y algodón. ${ }^{31}$

Sin embargo, la coyuntura de la elección presidencial, la cual se combinó con la del gobernador del estado en 1923, fue crucial para el inicio del reparto agrario en Rioverde. De hecho, la dotación de tierras resultó un mecanismo eficaz para ganar seguidores. ${ }^{32}$

Entre diciembre de 1923 y 1924, las resoluciones provisionales afectaron a las haciendas de El Jabalí, San Diego y Cieneguillas, pero sobre todo a la primera. Así, comenzaron a resolverse de manera positiva algunas de las solicitudes formuladas desde 1921, entre ellas las de El Pescadito, La Loma y El Aguacate, poblados ubicados dentro de los confines de la propiedad de El Jabalí. ${ }^{33}$ El propietario de la hacienda, Pablo Escandón, interpuso el recurso de amparo en todos los casos, cuestionando principalmente la categoría política de los poblados. ${ }^{34}$ Éstos fueron declarados rancherías en las constancias expedidas por el gobernador del estado con el fin de satisfacer el re-

${ }^{31}$ AHESLP, CAM, Rioverde, El Refugio, dotación, 1921, fs. 107-109.

${ }^{32}$ Véase el análisis en este sentido en Knight 2001, 327-363.

${ }^{33}$ CCJSLP, Juzgado $1^{\circ}$ de Distrito, Amparo, exp. 188/1925; AHESLP, CAM, Paquete 78, Rioverde, La Loma, dotación, 1922; AHESLP, CAM, Paquete 34, Rioverde, El Aguacate, ampliación, 1938.

${ }^{34}$ CCJSLP, Juzgado $1^{\circ}$ de Distrito, Amparo, exps. 188/1925 y 207/1928; AHESLP, CAM, paquete 78, Rioverde, La Loma, dotación, 1922. 
quisito de la categoría política que exigía el artículo $1^{\circ}$ del Reglamento Agrario de abril de 1922 para tener derecho a dotación. Sin embargo, los criterios para establecerla no eran claros y de hecho, resultó un elemento que se podía ajustar a las conveniencias de los gobernadores en turno.

De acuerdo con Escandón, los poblados solicitantes no debían catalogarse como rancherías puesto que las casas que formaban parte de los mismos habían sido construidas con el fin de albergar a los trabajadores de la hacienda con recursos aportados por él mismo. Atendiendo al reglamento agrario, en efecto, esos asentamientos debían catalogarse como poblados de trabajadores y no precisamente agrícolas; no obstante, por lo menos en estos primeros años en que el gobierno federal y el gobernador del estado estaban empeñados en ganar partidarios, las constancias de las categorías políticas declaraban rancherías a los poblados aunque no lo fueran, creándose una especie de clientela política para los grupos que se disputaban las riendas del gobierno estatal y federal. Si bien Escandón puso de manifiesto esta situación, las autoridades agrarias desecharon sus alegatos estipulando que el criterio del gobernador era inapelable en ese punto.

Con base en lo anterior, las dotaciones a El Pescadito, La Loma y El Aguacate resultaban discutibles, sin embargo, las más controversiales durante el gobierno de Aurelio Manrique fueron aquellas que involucraron a las tierras de riego de El Jabalí y de San Diego. Se trató de las dotaciones a los poblados de El Capulín y El Refugio (Picard-Ami 1980). En ambos casos se emitieron dos y hasta tres resoluciones provisionales, lo que era una trasgresión, ya que ninguna de las leyes agrarias facultaba a las instancias involucradas -gobierno del estado y presidencia de la república- a expedir más de una resolución con respecto a una solicitud en particular. Tales irregularidades tuvieron que ver con la pugna álgida sostenida entre los grupos antiagraristas y los agraristas más radicales, que se manifestó en Rioverde en este primer momento en el reparto de las mejores tierras. De hecho, Manrique y las autoridades agrarias locales pretendían socavar los recursos de las haciendas más productivas de Rioverde. Sin embargo, resaltó el especial encono hacia la hacienda de El Jabalí en los años de gobierno manriquista. Es posible que esa 
situación se debiera a que su propietario, Pablo Escandón y Barrón, era uno de los más conspicuos representantes del Porfiriato, además de haber sido gobernador del estado de Morelos.

El Capulín solicitó dotación de tierras en septiembre de 1922 y su expediente fue resuelto de manera negativa en agosto de 1923 por Lorenzo Nieto, sucesor de Rafael Nieto mientras se solucionaba la elección para la gubernatura de San Luis Potosí. El argumento central se basó en que se trataba de un poblado cuya categoría no se encontraba entre las contempladas por el Reglamento Agrario de 1922 como capacitadas para obtener tierras bajo cualquier modalidad, restitución o dotación. Esto es, de acuerdo con el dictamen de la Comisión Local Agraria era una estancia de El Jabalí en la que las casas habían sido construidas por el propietario de la hacienda con el fin de albergar a sus trabajadores que laboraban en la manufactura de la cańa de azúcar. Además, se consideró el amparo obtenido por Pablo Escandón en 1922. ${ }^{35}$ Sin embargo, en diciembre de 1923, cuando era un hecho que Manrique se había consolidado en el gobierno, se expidió una nueva resolución mediante la cual se dotó a El Capulín con 2,430 hectáreas, de las cuales 618 eran de riego. El Capulín gozaba de una posición ventajosa con respecto a los demás poblados de la hacienda de El Jabalí pues se localizaba en las inmediaciones de las tierras de la propiedad que se irrigaban con aguas del manantial de la Media Luna.

La resolución presidencial de El Capulín fue emitida en noviembre de 1924. En su texto se declaraba inexistente la resolución de Manrique en virtud de haber sido expedida por la misma persona moral en una segunda ocasión. Sin embargo, también se revocó la de agosto de 1923 en atención a que se consideró falso el argumento en que se fundamentaba su carácter negativo, esto es, que se trataba

${ }^{35}$ Véase el dictamen negativo de dotación de ejidos a El Capulín, emitido por la Comisión Agraria Mixta el 27 de agosto de 1923 debido a que se trataba de un grupo de habitantes cuyas habitaciones habían sido construidas por el propietario de la hacienda con el objeto de alojar a los trabajadores y por tanto se le aplicaba el artículo $3^{\circ}$ del Reglamento Agrario de abril de 1922, así como la resolución del gobernador del estado del 24 de agosto de 1923 en el que se respetan los términos del dictamen de la CaM y por tanto resulta negativa, en AHESLP, CAM, paquete 34, Rioverde, El Capulín, dotación, 1922. 
de un poblado de hacienda de los que caían en el artículo $3^{\circ}$ del Reglamento Agrario. ${ }^{36}$ Por el contrario, en la resolución presidencial se tomó en cuenta un documento expedido en septiembre de 1922 en el que el gobernador del estado hacía constar que El Capulín tenía carácter de ranchería. ${ }^{37}$ Así pues, la resolución presidencial terminó por respaldar la decisión de Manrique.

La dotación a El Refugio fue quizá más polémica que la de El Capulín pues solicitó dotación de tierras en 1921 y fue de hecho el primer poblado en solicitar tierras en Rioverde. ${ }^{38} \mathrm{Su}$ resolución provisional fue expedida en mayo de 1923 y después de ésta hubo dos resoluciones más del gobierno del estado, algo totalmente irregular que puede explicarse sólo en razón de la coyuntura de intensa pugna entre aquellos que consideraban que el desmembramiento de la hacienda de El Jabalí era un buen ejemplo de la destrucción de las grandes propiedades en la zona y quienes pretendieron proteger a la propiedad, incluso a costa de afectar más a la hacienda de Cieneguillas.

La solicitud fue resuelta el 12 mayo de 1923 por el gobernador Rafael Nieto, asignando la superficie afectable a las haciendas de Cieneguillas, San Diego y El Jabalí. No obstante, las afectaciones quedaron definidas en el caso de Cieneguilla, a la que se le consideraron 1,844 hectáreas, y de San Diego, a la cual se le fijaron 659, mas en el caso del Jabalí se declaró pendiente la determinación de la superficie y su ubicación. Este último punto causó controversia lo mismo entre los propietarios de Cieneguillas ${ }^{39}$ y El Jabalí que entre las autoridades de la Comisión Nacional Agraria y el gobernador del estado, pues se daba preferencia a los intereses de Pablo Escandón.

${ }^{36}$ En el Reglamento Agrario del 18 de abril de 1922 se establecía que los poblados ubicados dentro de las haciendas que no tuvieran definidas ninguna de las categorías políticas seńaladas en el artículo $1^{\circ}$, esto es, que se tratara de fincas que hubieran sido construidas con el propósito de alojar a los trabajadores dedicados a la explotación de las mismas propiedades no tendrían derecho a solicitar ejidos, excepto en el caso de que las haciendas hubieran sido abandonadas por sus propietarios y los núcleos de población tuvieran la necesidad de cultivar los terrenos de las inmediaciones con el fin de poder subsistir. Véase la fracción vi del artículo $1^{\circ}$ y el artículo $3^{\circ}$ de dicho reglamento. Reglamento Agrario de 18 de abril de 1922, en Fabila 1981, 327- 332.

${ }^{37}$ AHESLP, CAM, paquete 34, El Capulín, dotación, 1922.

${ }^{38}$ AHESLP, CAM, paquete 13, Ciudad Fernández, El Refugio, dotación, 1921.

${ }^{39}$ CCJSLP, Juzgado $1^{\circ}$ de Distrito, Amparo, exp. 66/1923. 
Tal conclusión se desprendía de la existencia de dos dictámenes previos de la Comisión Local Agraria en los que Escandón resultaba perjudicado por afectársele superficies de riego. En el primero de ellos se consideraban las siguientes superficies: de la hacienda de Cieneguillas se debían tomar 527 hectáreas, de la hacienda de San Diego se debían considerar 1,013 hectáreas y de la hacienda de El Jabalí, 1,480 hectáreas. Antonio Escandón, hijo y representante de Pablo Escandón, manifestó su desacuerdo con respecto a ese dictamen en virtud de que según él dentro de las 1,480 hectáreas afectadas a su propiedad se ubicaban entre 600 y 700 hectáreas de riego. El 9 de mayo de 1923, la Comisión Local Agraria expidió otro dictamen en el que la superficie afectable de El Jabalí se redujo a 507 hectáreas. ${ }^{40}$ Con todo, Escandón una vez más no estuvo de acuerdo, sobre todo por que consideraba que las 507 hectáreas indicadas formaban parte de las 7,800 que habían sido declaradas exentas de afectación mediante el decreto de 7 de octubre de 1922 por tener como finalidad el sostenimiento de las industrias en ella establecidas, cuestión que expresó sólo tres días antes de que se emitiera la resolución provisional. ${ }^{41}$

Pareciera que el gobernador del estado respondió nuevamente a las presiones de Antonio Escandón, pues en julio del mismo año, fuera de las formalidades establecidas por el Reglamento Agrario, mediante un oficio simple, dio a conocer finalmente las dimensiones de la superficie afectada a El Jabalí, lo mismo que la ubicación de ésta. Esta vez el predio señalado medía 1,014 hectáreas y se localizaba en el paraje conocido como "Las Magdalenas", cuya calidad era inferior a la de las 507 hectáreas consideradas en el dictamen de la Comisión Local Agraria del 9 de mayo de $1923 .{ }^{42}$ El gobernador trató de justificar la modificación mediante lo dispuesto en el decreto de 1922 que protegía las 7,800 hectáreas de la propiedad de los Escandón por formar parte de una unidad industrial.

El Jabalí sufrió un menoscabo más de sus tierras de riego a raíz de la resolución expedida por Aurelio Manrique en febrero de 1925

\footnotetext{
${ }^{40}$ AHESLP, CAM, paquete 13, El Refugio, Dotación, 1921.

${ }^{41}$ AHESLP, CAM, paquete 13, Ciudad Fernández, El Refugio, dotación, 1921.

${ }^{42}$ AHESLP, CAM, paquete 13, El Refugio, dotación, 1921.
} 
con el fin de dotar al poblado del casco de la hacienda, que en este caso solicitaron el administrador y algunos de los empleados de confianza del propietario. ${ }^{43}$ Esas tierras se regaban con aguas de la presa del mismo nombre, con lo cual se afectó casi la totalidad de la superficie de la propiedad beneficiada con el líquido que se almacenaba en ese vaso; de hecho con esta dotación las tierras de regadío de la hacienda quedaron reducidas a una pequeña porción que recibía agua del manantial de la Media Luna y un mínimo porcentaje de la superficie beneficiada con la presa de El Jabalí. En los meses posteriores a la dotación del poblado de El Jabalí, la relación entre el ejido y el propietario de la hacienda parece haber sido muy violenta, puesto que este último intentó preservar la posesión de las tierras ocupadas por cañaverales el mayor tiempo posible apegándose al artículo 19 del Reglamento Agrario de 1922. Aparentemente el administrador de la hacienda lejos de dejar extinguir la resoca de la caña existente comenzó a introducir renuevos con el fin de que el plazo para la desocupación se demorara, situación que de acuerdo con las autoridades agrarias locales y nacionales se podía prolongar indefinidamente. Los ejidatarios optaron por ocupar las tierras en abril de 1926, un año después de haber recibido la posesión provisional del resto de las tierras consideradas en su dotación. ${ }^{44}$

Independientemente de las dotaciones ya realizadas a La Loma, El Pescadito y El Aguacate, que comprendían quizá las mejores tierras de temporal de El Jabalí, las dotaciones a El Capulín, El Refugio y El Jabalí durante el gobierno de Aurelio Manrique fueron los golpes más severos para esa hacienda. El Capulín recibió gran parte de las tierras que se regaban con aguas de La Media Luna; El Refugio, por su parte, fue beneficiado con una superficie considerable de las tierras regadas con aguas de la presa de El Jabalí, así como con todas las tierras que la hacienda regaba por medio del canal de Ciudad Fernández, de acuerdo con el arreglo que tenía con el ayuntamiento

${ }^{43}$ AHESLP, CAM, paquete 34, Rioverde, El Jabalí, dotación, 1934.

${ }^{44}$ AGn, Presidentes, Obregón-Calles, exp. 818-C-106. Todo este expediente contiene la correspondencia entre Aurelio Manrique y el presidente municipal de Rioverde donde se revelan las contradicciones entre los ejidatarios del casco de la hacienda y los propietarios de la hacienda de El Jabalí. 
de esa ciudad; por último, el poblado de El Jabalí le afectó a la citada hacienda el resto de las tierras regadas a través de la presa de El Jabalí.

Por otro lado, el ejido de El Refugio también afectó parcialmente las tierras de riego de la hacienda de San Diego, aunque, se disputaría el agua de la presa existente con el poblado de San Diego, ubicado junto al casco de esta hacienda. Finalmente, El Refugio también afectó la limitada superficie de humedad de la hacienda de Cieneguillas, una hacienda que era principalmente de temporal y cuya principal riqueza radicaba probablemente en sus explotaciones forestales ubicadas en la Sierra Gorda. La humedad que recibían algunas de las tierras de Cieneguillas provenía de las filtraciones del canal de Ciudad Fernández. Con las tierras de riego que recibió, El Refugio se constituyó en uno de los ejidos más prósperos de Rioverde.

La hacienda de El Jabalí quedó así prácticamente desmantelada durante los años de gobierno de Aurelio Manrique. Sin sus tierras de riego y con varios juicios de amparo entablados simultáneamente por diversas razones, como las varias dotaciones ya realizadas, Escandón optó por desinstalar el ingenio y alambique que hasta entonces habían funcionado en su propiedad. Por si fuera poco, las deudas al erario del estado se comenzaron a acumular y terminaron por causar el embargo de varios de los predios de la hacienda, lo que condujo a la promoción de nuevos juicios de amparo. ${ }^{45}$ Pablo Escandón murió en 1926 y su hijo terminó por desistirse de todos los juicios que había promovido ante la Suprema Corte de Justicia de la Nación. La hacienda quedó abandonada, casi exclusivamente con sus tierras de peor calidad y sólo algunas pequeñas fracciones de tierras de riego fueron afectadas en los años siguientes sin que se opusiera ya resistencia.

La hacienda de San Diego también fue abandonada durante estos ańos. Además del fraccionamiento de sus tierras que supuso la dotación al ejido de El Refugio, esta hacienda fue afectada principalmente por el poblado de San Diego, cuya resolución provisional

${ }^{45}$ Pueden verse los juicios de amparo que fueron promovidos ante las autoridades judiciales por causa de los embargos promovidos por los adeudos de la propiedad al erario estatal en los siguientes expedientes, CCJLP, Juzgado $1^{\circ}$ de Distrito, Amparo, exp. 228/1925, exp. 182/1928, exp. 183/1928, exp. 59/1928 y exp. 100/1928. 
emitió Aurelio Manrique el 26 de febrero de 1925, el mismo día en que fue expedida la resolución provisional del poblado de El Jabalí. San Diego, adyacente al casco de esta hacienda, recibió 3,932 hectáreas, todas de la misma hacienda. ${ }^{46}$ De ellas, 417 eran de riego y 3,515 de agostadero. Ya en ese año la hacienda de San Diego quedó reducida a 731 hectáreas, de las cuales sólo 86 eran de riego, otras 86 de temporal, 485 eran de agostadero y 75 eran ocupadas por el casco, dentro del cual se incluyó el vaso de la presa (Amerlinck 1980, 287). Así, la mayor parte de las tierras de riego de San Diego fueron transferidas al ejido del mismo nombre. No obstante, el hecho de que las propietarias de la hacienda mantuvieran la presa bajo su propiedad implicó que tuvieran la posibilidad de controlar el flujo del agua hacia el ejido, lo que fue causando rencillas entre los ejidatarios y las propietarias (Amerlinck 1980, 288; Cabrera Ypiña y Cabrera Ypiña 1989, 150-155).

Se han puesto en tela de juicio las ideas de Saturnino Cedillo con respecto a los ejidos. De hecho, algunos de los autores que lo han estudiado lo acercan más a Calles por su preferencia hacia la pequeña propiedad (Falcón 1984, 212; 1988, 89-122; 2010, 47-71; Ankerson 1994). Sin embargo, la flexibilidad de su posición con respecto a la tenencia ejidal se puso de manifiesto en los momentos de crisis políticas. Cedillo no dudaba en acudir al reparto de tierras cuando así convenía a sus intereses. Así, casi inmediatamente que ocupó el ejecutivo del estado Cedillo se vio precisado a impulsar el reparto agrario. El movimiento cristero y el levantamiento escobarista fueron los factores explicativos de un nuevo auge de la reforma agraria entre 1927 y 1929, ya que le permitiría al gobierno federal contar con tropas entre aquellos que fueron beneficiados por las tierras. De las once resoluciones presidenciales positivas que tuvieron lugar durante estos ańos, seis de ellas incluyeron tierras de riego, aunque debemos tener en cuenta que de ellas la de Acequia Salada ya se encontraba en manos de los ejidatarios pues la resolución pro-

${ }^{46}$ Una década antes los campesinos de San Diego se negaron a tomar la tierra cuando se la ofrecieron los Cedillo, véase Falcón 1988, 99; Amerlinck 1980, 238 y ss. Aspecto que no es extraño, si se considera que muchos peones de varias partes de México se negaron a solicitar ejidos (Werner 1988, II, 165-168). 
visional se había emitido durante el gobierno de Aurelio Manrique, lo mismo que las de los poblados de El Jabalí y San Diego.

Otros ejidos que obtuvieron tierras de riego fueron La Reforma, Riachuelo y Pastora. El primer poblado afectó este tipo de tierras de las haciendas de Ojo de Agua de Solano y de Cieneguillas ubicadas en las riberas del río Verde. Riachuelo afectó una pequeña parte de las de la hacienda de San José del Tapanco, las cuales eran derivadas del manantial de la Media Luna a través del canal llamado río Enterrado. Por su parte, Pastora obtuvo una porción de las tierras irrigadas de la hacienda de La Angostura, hacienda que resentiría las principales afectaciones de sus tierras irrigadas hasta el periodo cardenista y en los primeros años de la década de 1940.

Entre 1930 y 1933, sólo se dieron cuatro resoluciones provisionales (Las Adjuntas, La Angostura, El Huizachal y San José del Tapanco), así como otras cuatro resoluciones presidenciales (Labor Vieja, Chupaderos, Las Adjuntas y La Angostura). Además, parece que la tendencia a detener el reparto agrario durante estos años se sumó también la propensión de evitar la dotación de tierras de riego. En esta tesitura algunas de las resoluciones provisionales fueron mucho más moderadas en la concesión de ese tipo de tierras. Por ejemplo, la resolución provisional de El Huizachal no incluyó tierras de riego, mientras que la presidencial la modificó, tomando en cuenta 192 hectáreas de riego. ${ }^{47}$

La desigualdad entre los ejidos con respecto a la distribución del agua fue uno de los resultados de la reforma agraria ${ }^{48}$ En el sur de Rioverde los sistemas de riego más importantes que pasaron a manos de los ejidos fueron dos de los que se desprendían del manantial de la Media Luna (canal de El Capulín y canal del río Enterrado), el que se derivaba de la presa de San Diego y el vinculado a la presa de El Jabalí. Estos sistemas de riego fueron controlados por ejidos que se formaron dentro de los límites de las haciendas de El Jabalí, San Diego, San José del Tapanco, Santa Isabel y Obrajero y Plazuela, quienes compartieron el agua, pero no lo hicieron en la misma medida.

${ }^{47}$ AHESLP, CAM, paquete 36, Rioverde, El Huizachal, dotación, 1929.

${ }^{48}$ Semejante a los casos de Morelos que trata Valladares (2003) y La Laguna que analiza Romero (2007). 
Los ejidos más agraciados fueron El Refugio, el Capulín, El Jabalí, San Diego y San José del Tapanco. El primero de ellos recibió parte del agua de la presa de El Jabalí o Laguna de Patos y todo el líquido que la hacienda de El Jabalí derivaba de la Media Luna a través del canal de Ciudad Fernández, el ejido El Jabalí recibió más de la mitad del agua que se almacenaba en la presa de El Jabalí; San Diego obtuvo la mayor parte del agua de la presa de San Diego, y El Capulín, junto con su dotación de tierras, recibió el derecho a regar gran parte de los terrenos de su ejido con el agua que se derivaba por el canal de El Capulín a partir del manantial de la Media Luna.

El desigual reparto del líquido tuvo que ver con factores de carácter político como los que hemos descrito párrafos anteriores, pero también con la inclinación del terreno y con los tipos de suelo, así como con la manera en que se proyectaron los diversos planos de las Comisiones Agrarias. Sin duda, sería importante profundizar en la visión de los ingenieros de las Comisiones, de cuyos informes se nutrió este trabajo, pero será una línea de investigación que por el momento quedará pendiente.

\section{Puntualización de los efectos en los Sistemas De Riego}

Una de las consecuencias del reparto de las tierras y del agua fue la desaparición del control de las obras hidráulicas que ejercían previamente los propietarios de las haciendas y que en casi todos los casos se encontraban dentro de sus tierras. Tanto el agua como las obras para distribuirla fueron asignadas a distintos ejidos. El resultado fueron los conflictos entre los mismos. Lamentablemente, son pocos los enfrentamientos que se encuentran bien documentados, pero permiten avizorar que por lo menos en algunos casos el corolario fue el deterioro y hasta la pérdida total de la infraestructura hidráulica construida por los dueños de las haciendas lo que, sin duda, mermó la capacidad productiva de los nuevos propietarios de tierras, aunque no sabemos a ciencia cierta si buscaron otras alternativas más viables para mantener la productividad de la tierra.

Uno de los conflictos que se ha podido reconstruir es el que tuvo lugar al repartirse el agua de las presas de las haciendas de San Diego y 
El Jabalí. Ya señalé que en los años de 1920 los ejidos de San Diego y El Refugio fueron favorecidos con dotaciones de tierras de riego que afectaban a la hacienda de San Diego. Sin embargo, la presa y los canales de alimentación de la misma quedaron en manos de la Sociedad Verástegui Hermanas, propietaria de la finca. ${ }^{49}$ Así, las hermanas Verástegui emplearon estrategias como la obstrucción de los canales de alimentación de la presa a partir de las aguas torrenciales provenientes de la Sierra Gorda. Asimismo, parte de la superficie del vaso fue azolvada con el fin de convertirla en campos de cultivo. De acuerdo con el informe del ingeniero de la Comisión Nacional Agraria, las propietarias lo hicieron con la finalidad de acondicionar terrenos en los que se pudiera sembrar por lo menos de humedad. Por el contrario, según Amerlinck (1980, 289), la Sociedad Verástegui Hermanas pretendía impedir que los ejidatarios se beneficiaran con el agua del vaso. Cualesquiera que haya sido la motivación principal de las propietarias, la consecuencia fue el deterioro de la presa, así como de los canales, y de esta manera ambos contendientes fueron perdiendo.

Por otra parte, la distribución del agua entre los ejidos de San Diego y El Refugio se vio afectada por la reducción de la capacidad de almacenamiento de la presa de San Diego. Así, al realizarse el estudio correspondiente se encontró que la presa no tenía la capacidad suficiente para regar las superficies de riego contempladas en las dotaciones de ambos ejidos. De acuerdo con una inspección practicada ni siquiera era posible regar las 417 hectáreas de riego concedidas al ejido de San Diego, pues, sólo había agua suficiente para proporcionar riego a 243 hectáreas. Lo anterior significaba reducir a El Refugio el volumen que se había considerado debía derivar de la presa de San Diego. Los derechos de ambos ejidos permanecieron indefinidos durante varios ańos, por lo menos hasta 1932, cuando un estudio permitió llegar a la conclusión de que no era posible conceder agua de la presa de San Diego a El Refugio. Mientras tanto, los ejidatarios de San Diego, en virtud de su proximidad a la presa, habían tratado de impedir el uso del agua a los de El Refugio. $\mathrm{Al}$ parecer los ejidatarios de ambos ejidos tuvieron que llegar a un

${ }^{49}$ AHESLP, CAM, Rioverde, San Diego, dotación, 1924. 
acuerdo provisional en tanto se definían los derechos al agua de ambos núcleos. Tal acuerdo consistió en que los de El Refugio se comprometieron a pagar cierta cantidad a los de San Diego con tal de que se les permitiera disponer del agua durante un mes y cinco días al año. Un reglamento fechado en 1934 da cuenta de que finalmente El Refugio no fue considerado en la distribución del agua de la presa de San Diego, la cual se repartió sólo entre el ejido de San Diego y las pocas tierras que le restaban a la hacienda después de las afectaciones que había sufrido. Al primero se le destinó $83 \%$ de la capacidad de almacenamiento de la presa para las 417 hectáreas de riego contempladas en su dotación, y a las segundas se les fijó $17 \% .^{50}$

Llama la atención que a pesar de lo estipulado en el Código Agrario de 1934, según el cual, cuando más de $75 \%$ de las tierras regadas perteneciera a ejidos, las obras hidráulicas debían pasar a manos de los mismos, la presa de San Diego y la infraestructura hidráulica continuó formando parte de la zona de protección del casco de la hacienda hasta 1941, por lo menos en el papel. Probablemente, ello se debía a la cercanía de la presa al casco, así como a la reducción que habían sufrido las tierras de la propiedad. Lo contradictorio, como se ha indicado antes, es que habiendo quedado en sus manos el vaso, las propietarias de la hacienda prácticamente se quedaron sin tierras que regar. Quizá por ello, así como porque casi todas las hermanas Verástegui fallecieron durante la década de 1920, la única heredera, Juana Verástegui, terminó por abandonar la propiedad. El ingenio fue desmantelado y la única sobreviviente de la familia se limitó a sobrevivir de lo que aportaba la huerta del casco (Cabrera Ypiña y Cabrera Ypiña 1989, 155). De esta forma, tanto la presa como el agua quedaron en realidad en manos de los ejidatarios de San Diego. Aparentemente, la situación cambió en 1941, cuando entraron nuevamente en competencia con otro núcleo ejidal, Buenavista, el cual se desprendió del ejido de San Diego.

Como se puede ver, las disposiciones de las autoridades agrarias, en este caso, tendían a propiciar el deterioro de la infraestructura, tanto porque las obras hidráulicas y los terrenos de riego quedaron

${ }^{50}$ AGA, Dotación de aguas, exp. 33/5459. 
sujetos a los intereses de diferentes ejidos, como por dotar las tierras ocupadas por la presa como tierras de riego o de humedad. Probablemente, la dotación de la superficie cubierta por las aguas de la presa como tierras de riego se debía a la escasez de tierras de esa calidad en la zona, de otra manera no se explica una decisión tan contradictoria por parte de los funcionarios de la Comisión Nacional Agraria.

Algo parecido a la de San Diego ocurrió con la presa El Jabalí. El agua que se almacenaba en la presa, proveniente de los arroyos de la Sierra Gorda, especialmente del arroyo La Loma, fue distribuida entre los ejidos de El Jabalí y de El Refugio. Al primero se le asignó $60 \%$ del agua y al segundo $36 \%$. El restante $4 \%$ quedó en manos de la hacienda de El Jabalí. En este caso la superficie ocupada por el vaso fue incluida dentro de las tierras dotadas a los ejidos de El Jabalí, El Aguacate y El Pescadito. Según un ejidatario de El Jabalí, el agua de la presa fue utilizada por los ejidos de El Jabalí y El Refugio hasta aproximadamente 1970. A partir de entonces la misma dejó de funcionar totalmente como resultado de que los ejidatarios de $\mathrm{El}$ Pescadito y El Aguacate comenzaron a invadir paulatinamente con sus sembrados los terrenos cubiertos por el agua. La cuestión era que estos ejidos no tenían derechos para usar el agua, además de que ésta les "agarraba de subida”, así que no la podían conducir por gravedad hasta sus tierras. Bajo estas circunstancias el agua de la presa perjudicaba más que beneficiaba en virtud de que significaba la reducción de la superficie aprovechable para sus siembras. Así, poco a poco, los sembradíos de ambos ejidos fueron ganándole terreno a la presa, como se ha podido comprobar hoy en día.

También podemos vislumbrar que la infraestructura de la hacienda de La Angostura se deterioró como resultado de la distribución de las tierras de riego entre los ejidos. En 1928, año cuando el poblado de Pastora recibió su dotación de tierras, se practicó una inspección al canal que se desprendía del manantial de San Tiburcio. A pesar de que el poblado había recibido una dotación en la que se incluían 229 hectáreas de riego, el agua que conducía ese canal no llegaba hasta el ejido. En el informe se indicó que el volumen ya no alcanzaba para cubrir las necesidades de los usuarios, pues, había disminuido considerablemente durante los últimos años como consecuencia de 
la primera distribución que se había efectuado. Inicialmente la única usuaria era la hacienda, pero hacia 1928 se incorporó el ejido de Pastora al recibir éste su dotación de tierras, en la que se incluyeron tierras de riego. Por otra parte, de manera aparentemente ilegal, los colonos de la colonia agrícola-militar de La Gavia, creada por Saturnino Cedillo a principios de los años veinte, también habían comenzado a hacer uso del agua aprovechándose de su situación en la parte alta del canal. De hecho, en el momento en que se practicó la inspección estos últimos estaban aprovechando prácticamente la totalidad del caudal que conducía normalmente el canal, para ello construyeron un dique que rebalsaba el agua y la elevaba hasta los terrenos de la colonia. El resultado de ese primer reparto fue que al finalizar la década de 1920 el canal se encontraba notablemente dańado. En todo su trayecto se encontraba azolvado y con vegetación que modificaba su corriente. Asimismo, en gran parte de su recorrido había sangrías e infiltraciones, así como desbordamientos. En suma, las pérdidas de líquido alcanzaban alrededor de $80 \%$ del volumen total del canal. ${ }^{51}$ Como consecuencia las tierras de riego de la hacienda habían disminuido, pero el más afectado era el ejido de Pastora pues el líquido no alcanzaba a llegar a sus tierras.

\section{Consideraciones finales}

Las ideas que han vertido varios autores en torno a cómo la reforma agraria vino a trastocar los sistemas de riego a partir de las dotaciones ejidales (tierra y agua), parece comprobarse plenamente en el caso de Rioverde. De esta manera una parte de la historia agraria e hídrica parece develarse como un proceso donde los ejidos fueron parcialmente desechando la infraestructura hidráulica, ya que en pocas ocasiones les beneficiaba para extender los cultivos que eran necesarios para la subsistencia. Uno de los resultados de la distribución del agua que formó parte del reparto agrario fue el deterioro parcial o total de algunas de las obras hidráulicas que habían sido levantadas por los dueños de las haciendas. Sin embargo, ese proceso

${ }^{51}$ AHESLP, CAM, Rioverde, Pastora, dotación, 1928. 
no necesariamente implicó un retroceso del área irrigada, pues a la par que algunas de las obras ya indicadas se perdían, comenzó a extenderse cada vez más la explotación de las aguas subterráneas. En distintos acervos que he consultado se encuentran evidencias del interés por utilizar pozos en la década de 1950, ya sea por parte de ejidatarios de manera individual o de ejidos completos. ${ }^{52}$ Los pozos se excavaban manualmente a una profundidad menor a los 15 metros y se instalaban equipos de bombeo que consistían en motores de combustión interna de alrededor de 10 caballos de potencia y bombas centrífugas con tubo de succión de tres o cuatro pulgadas. Para 1966, existían 226 pozos, de los que 179 eran a cielo abierto y 47 profundos, con más de 50 metros de profundidad. Los pozos profundos y las norias o pozos a cielo abierto se concentraron especialmente en el sur de Rioverde y en el noroeste, en los alrededores de Pastora.

De esta manera, los conflictos, no solamente entre los mismos ejidatarios por el acceso del agua, sino con los propietarios de las fraccionadas unidades productivas, llevaron a fuertes enfrentamientos, en muchos casos impulsados, cobijados o ignorados por las fuerzas políticas que estaban en las sillas gubernamentales, tanto en la ciudad de México como en la de San Luis Potosí. Sin embargo, ninguno de los actores fueron pasivos, tanto los hacendados como los ejidatarios utilizaron las armas legales que el gobierno federal a través de su legislación puso en manos de todos, como el relativo conservadurismo de algunos de los gobernadores potosinos para llevar a cabo el reparto de tierras y aguas. Lo que se puede apreciar de este hecho, es que en sí, muchas de las propiedades afectadas, al menos por Manrique, tenían una fuerte connotación de revancha en contra de aquellos que eran considerados adversarios del régimen.

La pregunta de por qué los ejidatarios no lograron mantener o sencillamente no les interesaba conservar la infraestructura hidráulica creada por las haciendas en el devenir de los siglos, encuentra

${ }^{52}$ Entre los documentos que evidencian el inicio de la explotación de las aguas subterráneas en la década de 1950 se pueden mencionar los siguientes: AHA, Consultivo Técnico, c. 587, exp. 5519; c. 587, exp. 5515 y c. 628, exp. 5992; AGN, Presidentes, Adolfo Ruiz Cortines, exp. 508.1/1221 y exp. 508.1/1303; AHA, Aprovechamientos Superficiales, c. 3986, exp. 55009, fs. 6-6v. 
una respuesta en la manera en cómo fue dividida la tierra y otorgada el agua, de esta forma no solamente ellos vieron cerrar ciertas posibilidades de manejar los recursos naturales, sino que los mismos intermediarios del gobierno (ingenieros y funcionarios agrarios) fueron poco conscientes de las implicaciones de este hecho, en aras de una justicia social que rompió el antiguo orden agrario sin proponer uno que llevará a la consolidación de los ejidos, muy diferentes al ejido colectivo cardenista. De esta manera, frente a la innovación agrícola, muchos de los propietarios del valle rioverdense se vieron en la necesidad de mejorar la manera de lograr un acopio mejor del agua, no solamente para canalizarlo a los terrenos destinados para eso, lo que los llevó a acentuar la disputa por el vital líquido.

Como se pudo apreciar, este artículo se une al esfuerzo que se ha estado realizando para cubrir una de las omisiones de los estudiosos de la reforma agraria, en el sentido de perder de vista la dimensión hidráulica, la cual no forzosamente va unida al aspecto agrario que se vio como una forma de "justicia social" para aquellos sectores rurales que habían sido desplazados del acceso y manejo de sus recursos naturales.

Sin duda, en los albores del siglo xx, el aprovechamiento del agua superficial que brotaba de los manantiales permanentes y de la que fluía por las corrientes perennes y estacionales del valle de Rioverde constituía un elaborado tejido de represas, canales, tajos, acequias y acueductos que las haciendas construyeron a partir del siglo XVII como un proceso de hidráulica incremental, que dio origen a amplias superficies irrigadas en esta porción de la cuenca del río Verde. Conocimiento, técnica, trabajo y capital de muchas generaciones de hacendados para el acondicionamiento del territorio sustentaron la producción hacendaria de cultivos comerciales como caña de azúcar, algodón... en las tierras así irrigadas y a la industria de transformación asociada. El paisaje que fue paulatinamente cambiado en los siglos coloniales, y que enfrentó un cambio importante durante el periodo de transición del siglo XIX al siglo xx, parece que encontró su "tragedia" durante el periodo ejidal.

El fraccionamiento de la superficie de las haciendas y su afectación en aras del reparto agrario y la dotación ejidal significó el colap- 
so de este sistema hidráulico, insostenible en la búsqueda de tierras de labor para la producción de cultivos de subsistencia. El territorio rioverdense se transformó en arena propicia de las disputas e intereses de las elites políticas y de la burocracia agraria, que junto con los cambios de los paisajes, presentará una cara diferente para las siguientes décadas, pero... eso es otra historia.

\section{SigLAS Y REFERENCIAS}

AGA, Archivo General Agrario, México. AGN, Archivo General de la Nación, México. AHESLP, Archivo Histórico del Estado de San Luis Potosí. AHA, Archivo Histórico del Agua, México. AHMR, Archivo Histórico Municipal de Rioverde, San Luis Potosí. BINAH, Biblioteca del Museo de Antropología, INAH, México. CCJsLP, Casa de la Cultura Jurídica de san Luis Potosí.

Авоites Aguilar, Luis, El agua de la nación. Una historia politica de México (1888-1946), México, Ciesas, 1988.

, "Historia de ríos. Un modo de hacer historia agraria en México”, en Antonio Escobar Ohmstede, Martín Sánchez Rodríguez y Ana Ma. Gutiérrez, coords., Agua y tierra en México, siglos XIX y XX, t. I, México, El Colegio de Michoacán, El Colegio de San Luis, México, 2008, 85-102.

Amerlinck, Mari-Jose, "From Hacienda to ejido: The San Diego de Rioverde Case", Tesis Philosophy in Anthropology P.h., State University of New Cork at Stoney Brook, 1980.

Ankerson, Dudley, El caudillo agrarista. Saturnino Cedillo y la Revolución mexicana en San Luis Potosí, México, Gobierno del Estado de San Luis Potosí, IneHrm, 1994.

BAzAnt, Jan, Cinco haciendas mexicanas, tres siglos de vida rural en San Luis Potosi (1600-1910), México, El Colegio de México, 1975.

Berumen, Claudia S., "Las aguas de la Media Luna en Rioverde, S.L.P. Manzana de la discordia y el deseo, 1894-1901", Tesis de Maestría en Historia, El Colegio de San Luis, 2005. 
, "La legislación decimonónica y la Media Luna (San Luis Potosí)", en Antonio Escobar Ohmstede, Martín Sánchez Rodríguez y Ana Ma. Gutiérrez, coords., Agua y tierra en México, siglos XIX y XX, t. I, México, El Colegio de Michoacán, El Colegio de San Luis, 2008, 103-124.

Boyer, Christopher, "Revolución y paternalismo ecológico: Miguel Ángel de Quevedo y la política forestal en México, 1926-1940”, en Historia Mexicana, vol. LviI, núm. 1, México, El Colegio de México, 2007, 91-138.

Cabrera Ypiña, Octaviano y Matilde Cabrera Ypiña de Corsi, Historia de la Hacienda de San Diego, Municipio de Río Verde, S.L.P., México, Editográfica Guadalajara, 1989.

CAмасно, Gloria, "Repartimientos de agua en el valle de Atlixco, 1592 y 1594: el Cantarranas y manantiales", en Boletín del Archivo Histórico del Agua, año 12, núm. 35, México, Conagua, Ciesas, 2007, 5-22.

"Desamortización y reforma agraria en Ocoyoacac y Lerma, 1856-1930", en Antonio Escobar Ohmstede, Martín Sánchez Rodríguez y Ana Ma. Gutiérrez, coords., Agua y tierra en México, siglos XIX y XX, t. I, México, El Colegio de Michoacán, El Colegio de San Luis, 2008, 287-311.

CASTAÑEDA, Rocío, Irrigación revolucionaria y reforma agraria: las comunidades de riego del valle de Santa Rosalia, Chihuahua, 1920-1945, México, Ciesas, Conagua, 1995.

, "La reglamentación del río del valle de Allende, Chihuahua, 1927-1930", en Boletín del Archivo Histórico del Agua, año 8, núm. 23, México, Conagua, Ciesas, 2003, 18-27.

"El Estado posrevolucionario visto desde su intervención en la gestión del agua en pequeños sistemas de riego, 19201940”, en Juan Manuel Durán, Martín Sánchez y Antonio Escobar Ohmstede, eds., El agua en la historia de México, México, CUCsH, Universidad de Guadalajara, El Colegio de Michoacán, 2005a, 237-262.

, Las aguas de Atlixco. Estado, haciendas, fábricas y pueblos, 1880-1920, México, Conagua, AHA, Ciesas, El Colegio de México, 2005b. 
Castañeda, Rocío, Antonio Escobar Ohmstede y Jorge A. Andrade, comps., Desastre económico o debilidad federal en los primeros gobiernos posrevolucionarios, México, CNA, AHA, Ciesas, UAEMEX, 2005.

Ervin, Michael A., "The 1930 Agrarian Census in Mexico: Agronomists, Middle Politics, and the Negotiation of Data Collection”, en Hispanic American Historical Review, vol. 87, núm. 3, 2007, 537-570.

Escobar Ohmstede, Antonio, "Cuatro momentos de un conflicto por el agua en San Luis Potosí: el caso de Rioverde, siglos XVIII-XX”, en Juan Manuel Durán, Martín Sánchez y Antonio Escobar, eds., El agua en la historia de México, México, Cucsh, Universidad de Guadalajara, El Colegio de Michoacán, 2005, 157-186.

, "El fraccionamiento privado y comunal en el oriente potosino durante la segunda mitad del siglo xIx. Una aproximación", en Antonio Escobar Ohmstede, Martín Sánchez Rodríguez y Ana Ma. Gutiérrez, coords., Agua y tierra en México, siglos XIX y $X X$, t. I, México, El Colegio de Michoacán, El Colegio de San Luis, 2008, 209-244.

"Estudio introductorio. Haciendas, pueblos y recursos naturales en San Luis Potosí”, en Antonio Escobar Ohmstede y Ana Ma. Gutiérrez, coords., Entretejiendo el mundo rural en el “oriente" de San Luis Potosí, siglos XIX y XX, México, Ciesas, El Colegio de San Luis, 2009, 19-98.

, "La legislación posrevolucionaria y su impacto en los sistemas de riego de las haciendas del valle rioverdense", en Antonio Escobar Ohmstede y José Alfredo Rangel Silva, coords., Haciendas, negocios y politica en San Luis Potosí, siglos XVIII al XX, México, El Colegio de San Luis, 2011, 263-311.

Escobar Ohmstede, Antonio e Israel Sandré Osorio, "Repartos agrarios 'en seco'. Agua y tierra en el Cardenismo", en Boletín del Archivo Histórico del Agua, año 12, núm. 36, México, Ciesas, Conagua, 2007, 70-87.

Escobar Ohmstede, Antonio y Ana Ma. Gutiérrez, "Estructuras agrarias en San Luis Potosí en la primera mitad del siglo xIx. El caso de la zona media y la Huasteca”, en Aurora Castillo Escalo- 
na y Rosa Martínez Pérez, coords., Estudios regionales. La propiedad de la tierra en la conformación regional: pasado y presente, México, Gobierno del Estado de Querétaro, Tribunal Superior de Justicia del Estado de Querétaro, Universidad Autónoma de Querétaro, 2008, 157-180.

Fabila, Manuel, Cinco siglos de legislación agraria, 1493-1943, México, CEHAM, SRA, 1981.

Falcón, Romana, Revolución y caciquismo en San Luis Potosí, 19101938, México, El Colegio de México, 1984.

"Carisma y tradición: consideraciones en torno a los liderazgos campesinos en la revolución mexicana. El caso de San Luis Potosi”, en Friedrich Katz, comp., Revuelta, rebelión y revolución. La lucha rural en México del siglo XVI al siglo XX, t. II, México, Ed. ERA, 1988, 89-122.

, "Esplendor y ocaso de los caciques militares. San Luis Potosí en la Revolución Mexicana", en Mexican Studies/Estudios Mexicanos, vol. 4, núm. 2, UCSD, 1988a, 265-293.

, "Los revolucionarios frente al antiguo régimen. El destino de las fincas intervenidas", en Relaciones. Estudios de Historia y Sociedad, vol. Ix, núm. 34, Zamora, El Colegio de Michoacán, 1988b, 83-118.

"Vínculos profundos y afectivos. Saturnino Cedillo y sus bases de apoyo campesino", en Carlos Martínez Assad, coord., El camino de la rebelión del general Saturnino Cedillo, México, Océano, 2010, 47-71.

FitTing, Elizabeth, “'Más sangre que agua’. Reclamos al estado en el valle de Tehuacán”, en Francisco J. Gómez Carpinteiro, ed., Paisajes mexicanos de la reforma agraria. Homenaje a William Roseberry, México, El Colegio de Michoacán, BUAP, CONACYT, 2007, 37-70.

Fortanelli, Javier, "Pequeña agricultura de regadío", en Tomás Martínez y Jacinta Palerm, eds., Antología sobre pequeño riego, vol. I, México, El Colegio de Posgraduados, 1997, 323-366.

Gómez Carpinteiro, Francisco, Gente de azúcar y agua, México, El Colegio de Michoacán, ICSH, BUAP, 2003.

, "Comunidades de agua en el Nexapa. Liberalismo y cen- 
tralización en el control local de recursos hidráulicos", en Francisco J. Gómez Carpinteiro, ed., Paisajes mexicanos de la reforma agraria. Homenaje a William Roseberry, México, El Colegio de Michoacán, BUAP, CONACYT, 2007, 133-165.

González, Adolfo, Álbum Rioverdense. Colección de escritos, datos históricos y estadísticas recogidas y coleccionadas por..., estudio introductorio y notas de Luz Carregha Lamadrid, México, El Colegio de San Luis, Ayuntamiento de Rioverde, 1902 [2002].

GonzÁlez Huerta, Margarita, "El sistema de riego de los manantiales de San Juan Teotihuacan”, en Jacinta Palerm y Tomás Martínez, eds., Antología sobre el pequeño riego. Organizaciones autogestivas, vol. II, México, El Colegio de Posgraduados, Plaza y Váldes Editores, 2000, 133-210.

KNight, Alan, "La política agraria en México desde la revolución", en Antonio Escobar Ohmstede y Teresa Rojas Rabiela, coords., Estructuras y formas agrarias en México, del pasado al presente, México, Ciesas, UQROO-RAN, 2001, 327-363.

"La Revolución mexicana: su dimensión económica, 1900-1930", en Sandra Kuntz, coord., Historia económica general de México. De la Colonia a nuestros días, México, El Colegio de México, Secretaría de Economía, 2010, 473-502.

Lanz Cárdenas, José T., Legislación de aguas en México, t. II, México, Consejo Editorial del Gobierno del estado de Tabasco, MéxiCo, 1982.

LERnER, Victoria, "Las zozobras de los hacendados de algunos municipios del oriente de San Luis Potosí (1910-1920)”, en Historia Mexicana, vol. xxxvi, núm. 2, México, El Colegio de México, 1986, 323-362.

, "La suerte de las haciendas: decadencia y cambio de propietarios (1910-1920)", en Historia Mexicana, vol. xxxvi, núm. 4, México, El Colegio de México, 1987, 661-697.

MÁrquez, Enrique y Horacio SÁnchez, "Fraccionamiento de las tierras de Felipe Barragán en el Oriente de San Luis Potosí, 1795-1905”, en Heriberto Moreno, coord., Después de los latifundios (La desintegración de la gran propiedad agraria en México), México, El Colegio de Michoacán, 1982, 49-60. 
Mendoza García, Édgar J., "Galerías filtrantes: la disputa por el agua del subsuelo en el valle de Tehuacán, 1900-1930", en Juan Manuel Durán, Martín Sánchez y Antonio Escobar Ohmstede, eds., El agua en la historia de México, México, $\mathrm{CUCH}$, Universidad de Guadalajara, El Colegio de Michoacán, 2005, 221-236.

NúŃEZ LunA, Alejandra, "Las aportaciones del jurista sobre las propiedades de las aguas: del rey a la nación", en Emilio Kourí, coord., En busca de Molina Enríquez. Cien años de Los grandes problemas nacionales, Jornadas 156, México, El Colegio de México, Centro Katz, The University of Chicago, 2009, 127228.

Ocampo F., Ignacio, "Niveles organizativos para el manejo de aguas en el valle de Atlixco", en Tomás Martínez y Jacinta Palerm, eds., Antología sobre pequeño riego, vol. I, México, El Colegio de Posgraduados, 1997, 367-398.

Palacios, Guillermo, "Julio Cuadros Caldas: un agrarista colombiano en la revolución mexicana", en Historia Mexicana, vol. xuIx, núm. 3, México, El Colegio de México, 2000, 431-476.

Palacios V., Enrique, “Sobre las Juntas de Agua”, en Jacinta Palerm y Tomás Martínez, eds., Aventuras con el agua. La administración del agua de riego: historia y teoría, México, Colegio de Posgraduados, 2009, 217-225.

Palerm, Jacinta, "El bimbalete o shaduf", en Jacinta Palerm, ed., Antología sobre pequeño riego. Sistemas de riego no convencionales, México, El Colegio de Posgraduados, vol. nII, 2002, 325-340.

, "Políticas del Estado para la administración de sistemas de riego y redes hidráulicas", en Juan Manuel Durán, Martín Sánchez y Antonio Escobar Ohmstede, eds., El agua en la historia de México, México, сuch, Universidad de Guadalajara, El Colegio de Michoacán, 2005, 263-289.

, José Luis Pimentel e Irma Salcedo, "Organización diferencial y escasez de agua: el caso del río Cuautla, Morelos", en Jacinta Palerm y Tomás Martínez, eds., Antología sobre el pequeño riego. Organizaciones autogestivas, vol. II, México, El Colegio de Posgraduados, Plaza y Váldes Editores, 2000, 73-96.

Pallares, Eduardo, Alegatos producidos por el lic...., en el juicio de 
amparo promovido por la Sociedad "Espinosa y Cuevas Hermanos" contra la sentencia dictada por la $1^{a}$. Sala del Tribunal Superior de Justicia del Distrito Federal en el juicio seguido por dicha Sociedad en contra los señores Bruno Rivero y Carmen Caloca de Rivero, México, Imprenta de Andrés Sánchez Juárez, 1912.

Picard-Ami Vogan, Ma. Luisa, "Agricultura comercial en un ejido de riego: el caso del Refugio, San Luis Potosi”, Tesis de Licenciatura en Antropología Social, México, Universidad Iberoamericana, 1980.

Rodríguez Meza, J. Guadalupe, "El Comité de Vigilancia de los ríos Atoyac y Nexapa: formación de una organización”, en Jacinta Palerm y Tomás Martínez, eds., Antología sobre el pequeño riego. Organizaciones autogestivas, vol. II, México, El Colegio de Posgraduados, Plaza y Valdés Editores, 2000, 345-406.

Romero Navarrete, Lourdes, "El reparto agrario y la redistribución del agua en La Laguna”, en Boletín del Archivo Histórico del Agua, año 8, núm. 24, Conagua, Ciesas, 2003, 21-26.

El rio Nazas y los derechos de agua en México: conflicto y negociación en torno a la democracia, 1878-1939, México, Ciesas, Universidad Autónoma de Coahuila, 2007.

SÁnchez Rodríguez, Martín, "El mejor de los titulos". Riego, organización social y administración de recursos hidráulicos en el Bajio mexicano, México, El Colegio de Michoacán, Gobierno del Estado de Guanajuato, Comisión Estatal del Agua, 2005.

, "El efecto del reparto agrario y la política hidráulica posrevolucionaria en la cuenca del Lerma", en Antonio Escobar Ohmstede, Martín Sánchez Rodríguez y Ana Ma. Gutiérrez, coords., Agua y tierra en México, siglos XIX y XX, t. II, México, El Colegio de Michoacán, El Colegio de San Luis, 2008, 375-400.

SANDRÉ, Israel, "Entre la subordinación y la autogestión, las juntas de aguas en la gestión del agua un caso: la Junta de Aguas del río Cuautitlán, 1922-1941”, en Juan Manuel Durán, Martín Sánchez y Antonio Escobar Ohmstede, eds., El agua en la historia de México, México, $\mathrm{CuCH}$, Universidad de Guadalajara, El Colegio de Michoacán, 2005, 289-322.

SANDré, Israel y Martín Sánchez Rodríguez, coords., El Eslabón 
perdido. Acuerdos, convenios, reglamentos y leyes locales de agua en México (1593-1935), México, Ciesas, 2011.

Tortolero, Alejandro, Notarios y agricultores. Crecimiento y atraso en el campo mexicano, 1780-1920, México, UAM/I, Siglo XXI Editores, 2008.

Valladares de la Cruz, Laura, Cuando el agua se esfumó. Cambios y continuidades en los usos sociales del agua en Morelos, 1880-1940, México, Fes-Cuautitlán (UnAM), 2003.

Werner Tobler, Hans, "Los campesinos y la formación del Estado revolucionario, 1910-1940", en Friedich Katz, comp., Revuelta, rebelión y revolución. La lucha rural en México del siglo XVI al siglo XX, t. II, México, Ed. ERA, 1988, 149-173.

FeCha de ReCepción del artículo: 22 de julio de 2011

FECHA DE RECEPCIÓN DE LA VERSIÓN FINAL: 15 de marzo de 2012 